San Jose State University

SJSU ScholarWorks

Master's Theses

Master's Theses and Graduate Research

1995

\title{
Evaluation and comparison of the 300-yard and 500-yard shallow water runs as field tests of aerobic power
}

Rebecca Barrett Cisar

San Jose State University

Follow this and additional works at: https://scholarworks.sjsu.edu/etd_theses

\section{Recommended Citation}

Cisar, Rebecca Barrett, "Evaluation and comparison of the 300-yard and 500-yard shallow water runs as field tests of aerobic power" (1995). Master's Theses. 1130.

DOI: https://doi.org/10.31979/etd.vvaa-7ymf

https://scholarworks.sjsu.edu/etd_theses/1130

This Thesis is brought to you for free and open access by the Master's Theses and Graduate Research at SJSU ScholarWorks. It has been accepted for inclusion in Master's Theses by an authorized administrator of SJSU ScholarWorks. For more information, please contact scholarworks@sjsu.edu. 


\section{INFORMATION TO USERS}

This manuscript has been reproduced from the microfilm master. UMI films the text directly from the original or copy submitted. Thus, some thesis and dissertation copies are in typewriter face, while others may be from any type of computer printer.

The quality of this reproduction is dependent upon the quality of the copy submitted. Broken or indistinct print, colored or poor quality illustrations and photographs, print bleedthrough, substandard margins, and improper alignment can adversely affect reproduction.

In the unlikely event that the author did not send UMI a complete manuscript and there are missing pages, these will be noted. Also, if unauthorized copyright material had to be removed, a note will indicate the deletion.

Oversize materials (e.g., maps, drawings, charts) are reproduced by sectioning the original, beginning at the upper left-hand corner and contimuing from left to right in equal sections with small overlaps. Each original is also photographed in one exposure and is included in reduced form at the back of the book

Photographs included in the original manuscript have been reproduced xerographically in this copy. Higher quality $6^{n} \times 9^{n}$ black and white photographic prints are available for any photographs or illustrations appearing in this copy for an additional charge. Contact UMI directly to order.

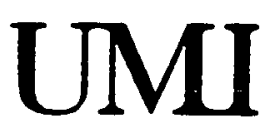

A Bell \& Howell Information Company 300 North Zeeb Road. Ann Afbor. MI 48106-1346 USA

313:761-4700 800:521-0600 



\title{
EVALUATION AND COMPARISON OF THE 300-YARD AND 500-YARD SHALLOW WATER RUNS AS FIELD TESTS OF AEROBIC POWER
}

\author{
A Thesis \\ Presented to \\ The Faculty of the Department of Human Performance \\ San Jose State University
}

\begin{abstract}
In Partial Fulfillment
of the Requirements for the Degree

Master of Arts
\end{abstract}

by

Rebecca Barrett Cisar

December 1995 
UMI Number : 1377221

Copyright 1995 by

Cisar, Rebecca Barrett

All rights reserved.

OMI Microform 1377221

Copyright 1996, by UMI Company. All rights reserved.

This microform edition is protected against unauthorized copying under Title 17, United States Code.

\author{
UMI \\ 300 North Zeeb Road \\ Ann Arbor, MI 48103
}


(C) 1995

Rebecca Barrett Cisar ALL RIGHTS RESERVED 
APPROVED FOR THE DEPARTMENT OF HUMAN PERFORMANCE Swan Wiekingm

Susan Wilkinson, Ph.D.

SPHTOOA

Endily $H$. Wughalter, Ed.D.

Leeration

Lee A. Walton, Professor of Human Performance

APPROVED FOR THE UNIVERSITY

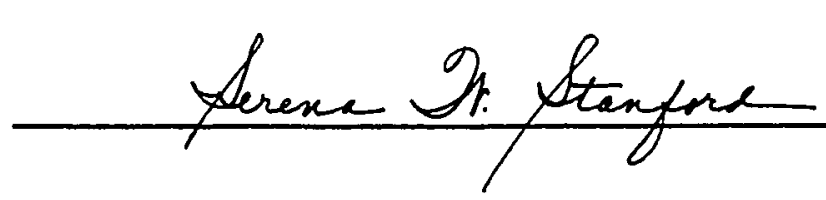




\section{ABSTRACT}

\section{EVALUATION AND COMPARISON OF THE 300-YD AND 500-YD SHALLOW WATER RUNS AS FIELD TESTS OF AEROBIC POWER}

\section{by Rebecca Barrett Cisar}

The study examined the validity of 300-yd and 500-yd shallow water run (SWR) tests to predict peak aerobic power (VO2peak), and cross-validated a previously developed 500-yd SWR test. Data collected on 18 women and 18 men included age, gender, body weight, height, leg length, percent body fat, $\mathrm{VO}_{2 \text { peak, and } 300 \text {-yd }}$ and 500-yd SWR times, heart rates, and ratings of perceived exertion. $\mathrm{VO}_{2 \text { peak }}$ was highly correlated to 300-yd and 500-yd SWR times ( $r=-.84$ and -.87 , respectively). Regression analysis revealed that prediction of $\mathrm{VO}_{2 \text { peak }}$ from 300-yd SWR time improved by including gender and body weight $\left(R=.919 ; S E E=0.360 \mathrm{~L} \cdot \mathrm{min}^{-1}\right)$. Prediction of $\mathrm{VO}_{2 \text { peak }}$ from 500-yd SWR time improved by including gender, body weight, and leg length $\left(R=.940 ; S E E=0.316 \mathrm{~L} \cdot \mathrm{min}^{-1}\right)$. Cross-validation of the previously developed 500-yd SWR test revealed that two of the three equations for predicting $\mathrm{VO}_{2 \text { peak }}$ were moderately valid. In conclusion, 300-yd and 500-yd SWR tests can provide valid estimates of aerobic power. 


\section{ACKNOWLEDGEMENTS}

The preparation of any document requires support and encouragement of many people without whom completion would be impossible. I should like to thank my parents, sister and brother, who have continually supported, challenged, and motivated my efforts for achievement and knowledge in human performance. Also, I thank my loving husband for the love, guidance, and encouragement he has shown me from the conception to the completion of this project. In addition, I thank my children for their understanding and patience. Furthermore, I thank my chairperson, Dr. Susan Wilkinson, for the constant support, guidance, and enthusiasm she has provided me, not only in my teaching, but from the beginning to the end of this project. I should also like to thank Dr. Emily Wughalter for her support not only as a colleague, but for providing the inspiration and motivation I needed to begin a project of this dimension, as well as her continued interest in finishing what $I$ thought not possible. I appreciated the technical skills of James Bowen who conscientiously assisted in the data collection. Last, but certainly not least, I thank Lee Walton for his dynamic and charismatic optimism, support, and intellect. 
TABLE OF CONTENTS

Abstract iv

Acknowledgements v v

List of Tables $\quad x$

CHAPTER $\quad$ Page

1. INTRODUCTION 1

Problem Statements 5

Hypotheses $\quad 6$

$\begin{array}{ll}\text { Limitations } & 7\end{array}$

$\begin{array}{ll}\text { Delimitations } & 7\end{array}$

$\begin{array}{ll}\text { Assumptions } & 7\end{array}$

Definition of Terms $\quad 8$

Importance of the Study 12

2. REVIEW OF LITERATURE 14

Previously Developed Submaximal Exercise

Field Tests to Predict Aerobic Power 15

$\begin{array}{ll}\text { Running Submaximal Field Tests } & 15\end{array}$

Walking and Jogging Submaximal Field Tests 20

Swimming Submaximal Field Tests 23

A Critical Evaluation of the Recently Developed 500-yd Shallow Water Run Field Test for the Estimation of Peak Aerobic Power 26

$\begin{array}{ll}\text { Summary } & 28\end{array}$

vi 
3. METHODS 31

$\begin{array}{ll}\text { Subjects } & 31\end{array}$

$\begin{array}{ll}\text { Apparatus } & 32\end{array}$

$\begin{array}{ll}\text { Procedures } & 33\end{array}$

Prior to Testing Methodology 33

Testing Methodology 33

Body Composition and Size $\quad 34$

Maximal Graded Exercise Test $\quad 34$

Shallow Water Run Tests $\quad 36$

$\begin{array}{ll}\text { Analysis of Data } & 38\end{array}$

4. RESULTS 41

Descriptive Characteristics and Gender Comparisons 41

Analysis of the Descriptive Characteristics and Gender Comparisons

Summary and Discussion of the Descriptive

Characteristics and Gender Comparisons 44

A Comparison of the Descriptive Characteristics and Gender Comparisons 
Correlation Coefficients for the Descriptive Characteristics of the Subjects 48

Analysis of the Correlation Coefficients for the Descriptive Characteristics of the Subjects

Summary and Discussion of the Correlation Coefficients for the Descriptive Characteristics of the Subjects

A Comparison of the Correlation Coefficients Previously Developed in the Kaminsky et al. (1993) Study

Multiple Regression Analyses $\quad \cdot \quad 54$

Multiple Regression Analyses $\quad 54$

Summary and Discussion of the Multiple Regression Analyses

$\begin{array}{ll}\text { Cross-Validation Analysis } & 61\end{array}$

Cross-Validation Analysis of the Multiple Regression Equations Developed by Kaminsky et al. (1993) for Predicting VO2peak

Summary and Discussion of the Cross-Validation Analysis of the Multiple Regression Equations Developed by Kaminsky et al. (1993) for Predicting $\mathrm{VO}_{2 p e a k}$ 
5. CONCLUSIONS 67

$\begin{array}{ll}\text { Summary } & 67\end{array}$

$\begin{array}{ll}\text { Conclusions } & 68\end{array}$

$\begin{array}{ll}\text { Weaknesses of the Study } & 69\end{array}$

$\begin{array}{ll}\text { Recommendations for Future Research } & 69\end{array}$

$\begin{array}{ll}\text { REFERENCES } & 70\end{array}$

APPENDICES

A. Statement of Informed Consent 76

B. Pre-Exercise Testing Health Questionnaire 86 


\section{LIST OF TABLES}

Table 1 Descriptive Characteristics and Gender

Comparisons of the Subjects

Page

43

Table 2 Matrix of Correlation Coefficients for the Descriptive Characteristics of the Subjects

Table 3 Multiple Regression Equations for Predicting Peak Oxygen Uptake Rate $\left(\mathrm{VO}_{2 \text { peak }}\right)$ from 300-yd Shallow Water Run (SWR) Time

Table 4 Multiple Regression Equations for Predicting Peak Oxygen Uptake Rate $\left(\mathrm{VO}_{2 \text { peak }}\right)$ from 500-yd Shallow Water Run (SWR) Time

Table 4 Multiple Regression Equations for Predicting Peak Oxygen Uptake Rate $\left(\mathrm{VO}_{2 \text { peak }}\right)$ from 500-yd Shallow Water Run (SWR) Time (continued)

Table 5 Multiple Regression Equations Previously Developed by Kaminsky et al. (1993) for Predicting Peak Oxygen Uptake Rate ( $\left.\mathrm{VO}_{2 \text { peak }}\right)$ from 500-yd Shallow Water Run (SWR) Time

Table 6 Cross-Validation of the Multiple Regression Equations (EQ) Previously Developed by Kaminsky et al. (1993) for Predicting Peak Oxygen Uptake Rate $\left(\mathrm{VO}_{2 \text { peak }}\right)$ from 500-yd Shallow Water Run (SWR) Time 


\section{Chapter 1}

INTRODUCTION

Aerobic power is related to the risk of cardiorespiratory diseases, circulatory diseases, and all-cause mortality in men and women (Blair et al., 1989). Aerobic power is a quantitative statement describing the peak amount of oxygen that can be utilized by the body during intense exercise. Aerobic power is one of the more important factors that determines an individual's ability to sustain moderate- to high-intensity exercise longer than four or five minutes.

The most accurate assessment of aerobic power is the direct measurement of peak oxygen uptake rate $\left(\mathrm{VO}_{2 p e a k}\right)$ during a graded exercise test (GXT) (Shepard, 1968; Taylor, Buskirk, \& Henschel, 1955). Direct measurements of $\mathrm{VO}_{2 \text { peak }}$ are primarily reserved for the laboratory because of costly equipment and the need for trained technicians. Despite high levels of accuracy, direct measurements of $\mathrm{VO}_{2 \text { peak }}$ are time consuming and impractical measurements for large numbers of individuals at one time. Instead, submaximal exercise tests have been devised to predict $\mathrm{VO}_{2 \text { peak }}$ in more ecologically valid contexts than the laboratory, such as in class situations which require fitness evaluations.

Submaximal field tests have been developed for different modes of exercise, such as bench stepping, cycle ergometry, and track walking and running. The selection of a field test to quantify aerobic power, based on the effects of a specific training program, 
should reflect the specific mode of exercise performed during training. The practical utility of submaximal field tests may be evaluated on the basis of four considerations: (a) the accuracy and validity of the prediction, (b) the ease and convenience of the testing protocol, (c) the relative risk of injury to the subject, and (d) the generalized application to a broad population (Kline et al., 1987).

Review of previous research which developed field tests to predict $\mathrm{VO}_{2 \text { peak, }}$, determined from $\mathrm{GXT}$, indicated that many studies (Falls, Ismail, \& MacLeod, 1966; Fox, 1973; Mastropaolo, 1970;

Ribisl \& Kachadorian, 1969) failed to present cross-validation results. In addition, many original and cross-validation studies (Cooper, 1968; Dolittle \& Bigbee, 1968; Getchell, Kirkendall, \& Robbins, 1977; Hermitson \& Faulkner, 1971; Maksud \& Coutts, 1971) did not report the standard errors of estimate and/or total errors, which limits the interpretation of accuracy when using the equations to predict $\mathrm{VO}_{2 \text { peak }}$ in other populations. Finally, many field tests have not taken into account individual differences in age, body weight, height, leg length, percent body fat, rating of perceived exertion (RPE), skill, fitness levels, and/or environmental conditions.

Some submaximal field tests have been reported to be accurate and valid predictors of $\mathrm{VO}_{2 p e a k}$ whereas other field tests have been found to be poor predictors of $\mathrm{VO}_{2 p e a k}$. For example, the popular Cooper's 12-min land-based walk/run test had high validity $(r=.90)$ 
as an indicator of treadmill $\mathrm{VO}_{2 p e a k}$ in men aged 17 to $52 \mathrm{yr}$ (Cooper, 1968). Subsequently, other investigators found the correlation coefficient between 12-min run time and $\mathrm{VO}_{2 \text { peak }}$ ranged from .49 (moderate) to .91 (high) in college-aged females (Custer \& Chaloupka, 1977; Johnson, Oliver, \& Terry, 1979; Katch, Pechar, McArdle, \& Weltman, 1973; Maksud, Cannistra, \& Dublinski, 1976). In contrast, the 12-min swim test has been reported to have low validity as a predictor of $\mathrm{VO}_{2 p e a k}$ determined from a tethered swim test in young adult male $(r=.40)$ and female $(r=.42)$ recreational swimmers, possibly due to the level of skill involved in swimming (Conley, Cureton, Dengel, \& Weyland, 1991; Conley, Cureton, Hinson, Higbie, \& Weyland, 1992). Likewise, the 12-min swim test was reported to have low validity as a predictor of $\mathrm{VO}_{2 \text { peak }}$ determined from a treadmill run in the male $(r=.38)$ and female $(r=$. 34) recreational swimmers (Conley et al., 1991; Conley et al., 1992), perhaps due to differences in the modes of exercise testing.

Recently, aquatic exercise has become a popular method of training and conditioning. Individuals of all fitness levels and health conditions are discovering that water exercise provides a relatively injury-free environment from physical injuries associated with land-based exercise. Specifically, aquatic exercise reduces the likelihood of injuries from high-impact, overuse, and heat-related problems typically associated with land-based exercise (Koszuta, 1986). Shallow water running, the most common 
mode of aquatic exercise (Midtlyng \& Nelson, 1991), has become a simple alternative, and/or supplement, to land-based running programs.

Although norms have been previously established for the 500-yd shallow water run (SWR) (Robbins, Powers, \& Burgess, 1991), the use of the 500-yd SWR as a submaximal field test of aerobic power was not established until recently (Kaminsky et al., 1993). Kaminsky et al. (1993) reported that 500-yd SWR time was a valid predictor of $V_{2 \text { peak }}\left(R=.79, S E E=5.14 \mathrm{ml}^{-1} \cdot \mathrm{kg}^{-1} \cdot \mathrm{min}\right)$ in men and women, particularly when percent body fat and height were taken into consideration $\left(R=.93, S E E=3.19 \mathrm{ml}^{-1} \cdot \mathrm{kg}^{-1} \cdot \mathrm{min}\right)$.

The 500-yd SWR test developed by Kaminsky et al. (1993) utilized a relatively homogeneous group of subjects in terms of age and fitness level $\left(\mathrm{VO}_{2 p e a k}\right.$ and percent body fat). In addition, Kaminsky et al. (1993) did not validate the developed prediction equations in a separate sample of subjects, or in a pool of different lengths/widths and/or water depth. Therefore, the ability to generalize the developed equations to a broader population may be limited.

The Kaminsky et al. (1993) study used a pool which sloped from a depth of 3.5 to $5 \mathrm{ft}$ in which the subjects completed the 500-yd SWR in a water depth mid-way between the navel and nipple line. Many shallow water runners use a pool of constant water depth; and consequently, it is not always possible to select a water depth level which corresponds to the depth of the water used in the 
Kaminsky et al. (1993) study. Therefore, height and/or leg length may be stronger predictor variables than previously identified in the equations developed to predict $\mathrm{VO}_{2 \text { peak. }}$ Also, it should be noted that the Kaminsky et al. (1993) study did not control for upper extremity action used during the 500-yd SWR, which could have affected the developed prediction equations.

Finally, the 500-yd SWR field test may be too strenuous and impose potential hazards to specific populations. Thus, the development of a field test with a protocol of shorter duration, such as a 300-yd SWR, may potentially pose less hazard and risk, reduce testing time, and yet still be of sufficient duration to predict VO 2 peak (Astrand \& Saltin, 1961; Katch et al., 1973). Therefore, the main intentions of the study were to (a) devise and evaluate the validity of a 300-yd shallow water run test to predict aerobic power, (b) improve the practical utility of the recently developed 500 -yd shallow water run test, and (c) cross-validate the recently developed 500-yd shallow water run test in a different pool and population.

\section{Problem Statements}

The specific purposes of the study were to determine: 1. To what extent did the variables of age, gender, body weight, height, leg length, percent body fat, $\mathrm{VO}_{2 \text { peak, }} 300$-yd SWR time, 300-yd SWR heart rate, and 300-yd SWR rating of perceived exertion, 500-yd SWR time, 500-yd SWR heart rate, and 500-yd SWR rating of perceived exertion intercorrelate with one another? 
2. To what extent did the predictor variables of age, gender, body weight, height, leg length, percent body fat, 300-yd SWR time, 300-yd SWR heart rate, and 300-yd SWR rating of perceived exertion combine to account for the variance in $\mathrm{VO}_{2 p e a k}$ ?

3. To what extent did the predictor variables of age, gender, body weight, height, leg length, percent body fat, 500-yd SWR time, 500-yd SWR heart rate, and 500-yd SWR rating of perceived exertion combine to account for the variance in $\mathrm{VO}_{2 \text { peak? }}$ ?

4. To what extent did the three equations developed by Kaminsky et al. (1993) predict $\mathrm{VO}_{2 \text { peak }}$ in the current study?

Hypotheses

The following null hypotheses were made for the purposes of the study:

1. The variables of age, gender, body weight, height, leg length, percent body fat, VO2peak, 300-yd SWR time, 300-yd SWR heart rate, and 300-yd SWR rating of perceived exertion, 500-yd SWR time, 500-yd SWR heart rate, and 500-yd SWR rating of perceived exertion did not intercorrelate with one another.

2. The predictor variables of age, gender, body weight, height, leg length, percent body fat, 300-yd SWR time, 300-yd SWR heart rate, and 300-yd SWR rating of perceived exertion did not combine to account for the variance in $\mathrm{VO}_{2 \text { peak }}$.

3. The predictor variables of age, gender, body weight, height, leg length, percent body fat, 500-yd SWR time, 500-yd SWR heart rate, 
and 500-yd SWR rating of perceived exertion did not combine to account for the variance in $\mathrm{VO}_{2 \text { peak. }}$

4. The multiple regression equations developed by Kaminsky et al. (1993) were not reasonable predictors of $\mathrm{VO}_{2 p e a k}$ in the current study.

\section{Limitations}

The study was limited to:

1. A thermoneutral water temperature of $28^{\circ} \mathrm{C}\left(82^{\circ} \mathrm{F}\right)$. At this temperature, the metabolic heat generated during exercise is easily transferred to the water, yet the gradient for heat flow does not cause a significant increase in energy cost or change in core temperature due to cold stress (McArdle, Katch, \& Katch, 1991).

2. A fairly constant water depth of $3.5 \mathrm{ft}$ (42 in.) during the shallow water run throughout the 25 yd length.

\section{Delimitations}

The study was delimited to apparently healthy female subjects aged $28.58 \pm 7.41 \mathrm{yr}(M \pm S D)$ and male subjects aged $27.32 \pm 5.40 \mathrm{yr}$ because the American College of Sports Medicine (1991) did not recommend physician supervision for exercise testing of healthy subjects within these age ranges.

\section{Assumptions}

The following assumptions were made for the purposes of the study:

1. Each subject understood the directions given to him or her. 
2. Each subject put forth his or her best effort. Uninformed and less motivated individuals may not have performed maximally on the run tests which may have affected the validity of the study.

\section{Definition of Terms}

Age: The length of time that a person has existed since birth. Age was measured in years and months.

Body density (DB): Body density was determined using the skinfold equations published by Pollock, Schmidt, and Jackson (1980). The density of the body, or body density, was expressed as body weight per body volume, or in kilograms per liter $\left(\mathrm{kg} \cdot \mathrm{L}^{-1}\right)$.

Body weight (BW): The gravational force that is naturally exerted on the body; body weight is a product of body mass and acceleration due to gravity in $\mathrm{kg}$ (Kent, 1994). Body weight was expressed in kilograms $(\mathrm{kg})$.

Five hundred-yard shallow water run heart rate (500-yd SWR HR): Post-run heart rate was recorded and averaged from the first $15 \mathrm{~s}$ immediately following completion of the 500-yd shallow water run test using a Polar Vantage $X^{\top M}$ heart rate monitor. The 500-yd SWR HR was expressed in beats per minute (b.min $\left.{ }^{-1}\right)$.

Five hundred-yard shallow water run rating of perceived exertion at completion (500-yd SWR RPE): Rating of perceived exertion (RPE) is a method of quantifying subjective exercise intensity (American College of Sports Medicine, 1991). RPE closely correlates with physiological variables which increase linearly with increasing exercise intensity, such as oxygen uptake rate, heart 
rate, and minute ventilation rate (American College of Sports Medicine, 1991). Borg's scale of perceived exertion, was used to measure RPE; the odd numerical ratings on the scale are associated with subjective descriptions ranging from very, very light (7) to very, very hard (19) (American College of Sports Medicine, 1991). The RPE was recorded during the last $5 \mathrm{~s}$ of the 500-yd SWR test (500-yd SWR RPE).

Five hundred-yard shallow water run time (500-yd SWR Time): A 500-yd (20 laps) timed run in a 25-yd swimming pool with a water temperature of $280 \mathrm{C}\left(82^{\circ} \mathrm{F}\right)$ and a water depth of $106.68 \mathrm{~cm}(3.5 \mathrm{ft}$ or 42 in.). Each subject ran forward as fast as possible for the entire distance of 500-yd. The arm actions perfomed were similar to the arm movements used to swim the front crawl. Specifically, the "recovery" portion of the armstroke was performed through the air; and, the "propulsive" phase was performed as the fingertips entered the water and continued to sweep the submerged hand and arm past the hip. The level that the arm was submerged depended on the subject's height, motivation, need for balance, and possible swimming skills. The total time of the run was recorded in minutes and seconds.

Height: The standing distance of stature measured from the the top of the head to the floor using a Broca plane. Height was expressed in centimeters $(\mathrm{cm})$.

Leg length: The distance from the greater trochantor to the floor measured in the standing position (Kaminsky et al., 1993) using 
a Broca plane. Leg length was was averaged from the measurements of both right and left legs and expressed in centimeters (cm).

Oxygen uptake rate $\left(\mathrm{VO}_{2}\right)$ : The rate at which the body's tissues extract oxygen to meet the muscle's energy demands. Oxygen uptake rate in liters per minute $\left(L \cdot \mathrm{min}^{-1}\right)$ represents the total capacity of the cardiorespiratory system. Since $\mathrm{VO}_{2}$ in L.min-1 is related to body size, large people have greater values than smaller people. Oxygen uptake rate in milliliters per kilogram of body weight per minute $\left(\mathrm{ml}^{\mathrm{kg}} \mathrm{kg}^{-1} \cdot \mathrm{min}^{-1}\right)$ corrects for differences in body weight (McArdle et al., 1991).

Peak oxygen uptake rate ( $\mathrm{VO}_{2 \text { peak }}$ ): Peak oxygen uptake rate is the point at which oxygen uptake rate plateaus or decreases with increasing workloads, heart rate is within $10 \mathrm{~b} \cdot \mathrm{min}^{-1}$ of agepredicted peak heart rate (220 - age in years), and/or the respiratory exchange ratio $\left(\mathrm{VCO}_{2} \cdot \mathrm{VO}_{2}{ }^{-1}\right)$ is greater than 1.0 (McArdle et al., 1991). $\mathrm{VO}_{2 \text { peak }}$ is also referred to as peak aerobic power and is generally considered to be the best measure of cardiorespiratory fitness (McArdle et al., 1991). Some investigators refer to $\mathrm{VO}_{2 \text { peak }}$ as peak oxygen consumption, or peak oxygen uptake. $\mathrm{VO}_{2 \text { peak }}$ was determined from graded treadmill exercise testing (GXT) which utilized a MedGaphics Cardiopulmonary Exercise System CPXID ${ }^{\mathrm{TM}}$. $\mathrm{VO}_{2 \text { peak }}$ was expressed in both liters per minute $\left(L \cdot \mathrm{min}^{-1}\right)$ and mililiters per kilogram per minute $\left(\mathrm{ml}^{-1} \cdot \mathrm{kg}^{-1} \cdot \mathrm{min}^{-1}\right)$.

Percent body fat (\%BF): Percent body fat is the percentage of body weight consisting of adipose weight and was calculated from 
the following formula: percent body fat $=[(495 /$ body density $)-450]$ (Siri, 1961).

Three hundred-yard shallow water run heart rate (300-yd SWR HR): Post-run heart rate was recorded and averaged from the first $15 \mathrm{~s}$ immediately following completion of the 300-yd shallow water run test using a Polar Vantage $X L^{\mathrm{TM}}$ heart rate monitor. The 300-yd SWR HR was expressed in beats per minute $\left(b \cdot \min ^{-1}\right)$.

Three hundred-yard shallow water run rating of perceived exertion at completion (300-yd SWR RPE): Rating of perceived exertion (RPE) is a method of quantifying subjective exercise intensity (American College of Sports Medicine, 1991). RPE closely correlates with physiological variables which increase linearly with increasing exercise intensity,.- such as oxygen uptake rate, heart rate, and minute ventilation rate (American College of Sports Medicine, 1991). Borg's scale of perceived exertion, was used to measure RPE; the odd numerical ratings on the scale are associated with subjective descriptions ranging from very, very light (7) to very, very hard (19) (American College of Sports Medicine, 1991). The RPE was recorded during the last $5 \mathrm{~s}$ of the 300-yd SWR test (300-yd SWR RPE).

Three hundred-yard shallow water run time (300-yd SWR

Time): A 300-yd (12 laps) timed run in a 25-yd swimming pool with a water temperature of $28^{\circ} \mathrm{C}\left(82^{\circ} \mathrm{F}\right)$ and a water depth of $106.68 \mathrm{~cm}$ (3.5 $\mathrm{ft}$ or 42 in.). Each subject ran forward as fast as possible for the entire distance of 300-yd. The arm actions perfomed were 
similar to the arm movements used to swim the front crawl. Specifically, the "recovery" portion of the armstroke was performed through the air; and, the "propulsive" phase was performed as the fingertips entered the water and continued to sweep the submerged hand and arm past the hip. The level that the arm was submerged depended on the subject's height, motivation, need for balance, and possible swimming skills. The total time of the run was recorded in minutes and seconds.

\section{Importance of the Study}

Field tests have been used both as an indication of fitness, as well as providing a method of monitoring changes in fitness levels. Shallow-water running field tests may provide alternative assessment tools for the physically fit, those who cannot perform land-based running due to injuries, or for special populations that cannot perform land-based modes of exercise testing. As shallowwater running proliferates rapidly as an alternative, and/or supplemental, method of training, valid and practical field tests are needed to serve as alternative assessment tools. Thus, the specific importance of this study was to (a) develop a safe and valid SWR field test that was shorter, and more practical than the 500-yd SWR test to predict aerobic power in men and women; (b) cross-validate the recently developed 500-yd SWR field test in a different pool and population; and (c) improve the practical utility of the previously developed 500-yd SWR test. In doing so, the 300-yd and 500-yd SWR tests may serve as practical assessment tools in the classification 
of an individual's fitness level based on broad categories, such as poor, fair, good, and excellent. 
Chapter 2

\section{REVIEW OF LITERATURE}

Aerobic power determines the peak amount of oxygen that can be utilized by the body during moderate- to high-intensity exercise lasting longer than four or five minutes. The direct measurement of peak oxygen uptake rate $\left(\mathrm{VO}_{2 \text { peak }}\right)$ during a graded exercise test is the most accurate assessment of aerobic power (Taylor et al., 1955; Shepard, 1968); however, the direct measurement of $\mathrm{VO}_{2 p e a k}$ has limited practical utility. Instead, submaximal exercise tests have been devised to predict aerobic power. An extensive review of the literature confirms the specific need for (a) the development of a safe and valid SWR field test that is shorter and more practical than the 500-yd SWR test to predict aerobic power in men and women, (b) the cross-validation of the recently developed 500-yd SWR test developed by Kaminsky et al. (1993) in a different pool and population, and (c) an improvement in the practical utility of the previously developed 500-yd SWR test.

Chapter 2 is divided into two subheadings which include (1) previously developed submaximal exercise field tests to predict aerobic power; and, (2) a critical evaluation of the recently developed 500-yd SWR test used to predict aerobic power. The Chapter is organized to present a review of literature which establishes a foundation for the study of the 300-yd and 500-yd SWR field tests as predictors of aerobic power. Chapter 2 concludes with a brief summary. 
Previously Developed Submaximal Exercise Field Tests to Predict Aerobic Power

The purpose of the following section is to review studies that have previously developed submaximal exercise field tests for the prediction of aerobic power. Investigations of various submaximal exercise tests have been developed to predict aerobic power, including running (Balke, 1963; Cooper, 1968), walking (A. Jackson, Solomon, \& Stusek, 1992; Kline et al., 1987), jogging (George, Vehrs, Allsen, Fellingham, \& Fisher, 1992; George, Vehrs, Allsen, Fellingham, \& Fisher, 1993), swimming (Conley et al., 1991; Conley et al., 1992), cycling (Astrand \& Ryhming, 1954), aerobic dance (Rogers-Johnson, Heyward, Schau, \& Cagle, 1992), bench stepping (Margaria, Aghemo, \& Rovelli, 1965), deep water running (Sherman, Michaud, \& Ryan, 1993), and shallow water running (Kaminsky et al., 1993). The studies reviewed in the subsequent section include running, walking and jogging, and swimming field tests developed to predict aerobic power. The validity, reliability, and practical utility of the studies predicting $\mathrm{VO}_{2 p e a k}$ from the various field tests will be discussed.

\section{Running Submaximal Field Tests}

Balke's investigation (1963) established the basis for a simple field test as a measure of aerobic power. With eight male military subjects, a best effort 12-min run for distance revealed an oxygen uptake rate $\left(\mathrm{VO}_{2}\right)$ mean of $46.7 \mathrm{ml} \cdot \mathrm{kg}^{-1} \cdot \mathrm{min}^{-1}$ ciosely related to the mean treadmill $V_{2 \text { peak }}$ value of $46.1 \mathrm{ml} \cdot \mathrm{kg}^{-1} \cdot \mathrm{min}^{-1}$. The 
subjects mean $\mathrm{VO}_{2}\left(52.6 \mathrm{ml} \cdot \mathrm{kg}^{-1} \cdot \mathrm{min}^{-1}\right)$ for a best effort 5 -min run for distance exceeded the measured $\mathrm{VO}_{2 \text { peak, }}$ and the mean $\mathrm{VO}_{2}$ (43.8 $\mathrm{ml}^{1} \mathrm{~kg}^{-1} \cdot \mathrm{min}^{-1}$ ) for a best effort 20-min run for distance underestimated the measured $\mathrm{VO}_{2 p e a k}$. The mean $\mathrm{VO}_{2}$ values for the $5-, 12-$, and $20-$ min runs were derived from the average running speed during each of the runs, and estimates of oxygen demands were based on the linear relationship between running speed and steady-state $\mathrm{VO}_{2}$

It is interesting to note that in Balke's (1963) study, the $\mathrm{VO}_{2 \text { peak }}$ estimations from 12-min run average speed closely related to the $\mathrm{VO}_{2}$ measured during 12-min run performances. Balke concluded that a 12-min best-effort run can be utilized as a substitute for a standard work capacity test in the laboratory. Results were interpreted with caution due to the small sample size of military personnel who were likely to be highly motivated.

As an offshoot of Balke's original work, Cooper (1968) correlated $\mathrm{VO}_{2 \text { peak }}$ with a 12 -min run field test in 115 military males ranging in age from 17 to $52 \mathrm{yr}$. The treadmill $\mathrm{VO}_{2 \text { peak }}$ data were compared with the distance completed during the 12-min run test. A high correlation coefficient $(r=.90)$ was found between measured treadmill $\mathrm{VO}_{2 \text { peak }}$ and the 12-min run performance. The sample size was large; however, similar to Balke's study, the subjects were again military personnel who were likely to be highly motivated. Both of these early studies (Balke, 1963; Cooper, 1968), utilizing submaximal running performance to predict $\mathrm{VO}_{2 \text { peak, failed }}$ 
to report the standard errors of estimate (SEE), which makes it difficult, if not impossible, to determine the expected amount of errors in predicting $\mathrm{VO}_{2 \text { peak }}$ when using these tests.

Since 1968, many studies have reported a wide range of validity coefficients $(r=.28$ to .94$)$ for $\mathrm{VO}_{2 \text { peak }}$ and distance run tests of at least one mile or $9 \mathrm{~min}$. The results of 34 validity studies, 10 test reliability studies, and 10 criterion reliability studies involving distance run field tests predicting treadmill $\mathrm{VO}_{2 \text { peak }}$ were examined through an extensive search of published and unpublished literature (Safrit, Glaucia Costa, Hooper, Patterson, \& Ehlert, 1988). The purpose of the Safrit et al. (1988) study was to establish the generalizability of distance run tests using a metaanalysis model design.

Concurrent validity was of primary interest to Safrit et al. (1988). Concurrent validity was defined as the extent to which the ability on a field test reflects the concurrent ability on a criterion measure $\left(\mathrm{VO}_{2 \text { peak }}\right)$. Interestingly, the concurrent validity of the distance run tests was not shown to be generalizable across all situations. Distance run tests of 1 to 1.5 miles had only moderately high concurrent validity. It is usually assumed that a distance run test will be equally valid for a similar group of subjects in a similar environment. Unfortunately, there is no evidence that a test established as valid in one setting (situation-specific) will possess approximately the same validity if used with a different group of subjects with similar characteristics. The results of the Safrit et 
al. (1988) meta-analysis demonstrated the importance of validating the recently developed 500-yd shallow water run test developed by Kaminsky et al. (1993) in a different pool and population.

When the data in the Safrit et al. (1988) study were analyzed separately for men and women it was found that the distance run tests performed by women had greater generalizability than the run tests performed by men. Overall, the studies in the Safrit et al. (1988) analysis included more highly trained men than women. Low fit subjects are generally less motivated to perform maximally on the run tests, and therefore would contribute to lowering the validity coefficient. Unfortunately, the exclusion of low fit subjects may limit the generalizability of the prediction equations to more diverse populations than the specific populations used in original investigations.

Safrit et al. (1988) made a plea requesting future studies to include detailed information of the subjects' fitness levels in hopes of making the studies more valuable. In sum, the results of the major study by Safrit et al. (1988) indicated that distance run test validity is not merely situation-specific; gender, and levels of fitness, were also confounding variables which affected the generalizability of the results.

In a more recent analysis of the 12-min track run as a predictor of aerobic power, McCutcheon, Sticha, Giese, and Nagle (1990) studied 30 relatively fit subjects (15 females and 15 males) aged $25.2 \pm 4.8 \mathrm{yr}(M \pm S D)$. The subjects performed a maximal 


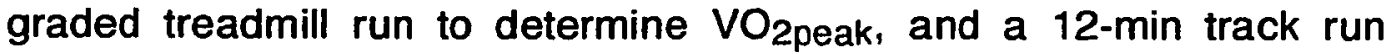
for metric distance. The distance run that was completed in $12 \mathrm{~min}$ was divided by time to determine the average running velocity. $\mathrm{V}_{2 \text { peak }}$ was predicted from the average running velocity using the metabolic prediction equation developed by the American College of Sports Medicine (American College of Sports Medicine, 1991). There was a high correlation ( $\left.r=.90, S E E=2.9 \mathrm{ml} \cdot \mathrm{kg}^{-1} \cdot \mathrm{min}^{-1}\right)$ between $\mathrm{VO}_{2 \text { peak }}$ determined from the graded treadmill run and the predicted $\mathrm{VO}_{2}$, determined from the 12-min track run.

Interestingly, McCutcheon et al. (1990) reported that the predicted $\mathrm{VO}_{2 \text { peak }}$ from the 12 -min run was approximately $7 \%$ lower than the actual $\mathrm{VO}_{2 \text { peak }}$ measured during the graded treadmill run $\left(52.6 \pm 6.7\right.$ versus $\left.56.4 \pm 8.3 \mathrm{ml} \cdot \mathrm{kg}^{-1} \cdot \mathrm{min}^{-1} ; M \pm S D\right)$. Consequently, the total error in the prediction of $\mathrm{VO}_{2 p e a k}$ from the 12-min run was approximately $6-7 \mathrm{ml} \cdot \mathrm{kg}^{-1} \cdot \mathrm{min}^{-1}$ (SEE of $2.9 \mathrm{ml} \cdot \mathrm{kg}^{-1} \cdot \mathrm{min}^{-1}$ plus mean difference of $3.8 \mathrm{ml} \cdot \mathrm{kg}^{-1} \cdot \mathrm{min}^{-1}$ ). The total error in the prediction of $\mathrm{VO}_{2 \text { peak }}$ clearly demonstrated the need for considering both the SEE and mean difference in predicted $\mathrm{VO}_{2 \text { peak }}$ versus actual $\mathrm{VO}_{2 p e a k}$, when cross-validating a previously developed metabolic prediction equation.

In summary, the results of the study by McCutcheon et al. (1990) indicated that the estimated $\mathrm{VO}_{2 \text { peak }}$ values from a $12-\mathrm{min}$ track run were highly correlated to actual $\mathrm{VO}_{2 p e a k}$ values measured during a graded treadmill run test. The mean estimated $\mathrm{VO}_{2 \text { peak }}$ value from the American College of Sports Medicine (ACSM) 
metabolic prediction equation was approximately $7 \%$ lower than the actual mean $\mathrm{VO}_{2 \text { peak }}$ value obtained during the graded treadmill run test. The underestimation of the actual $\mathrm{VO}_{2 \text { peak }}$ from the field test indicated that a revision of the existing ACSM equation, based on the data from the McCutcheon et al. (1990) study, may have improved the correlation, and reduced the standard error of estimate between the field and laboratory tests. Therefore, revisions in existing metabolic prediction equations may more closely approximate the

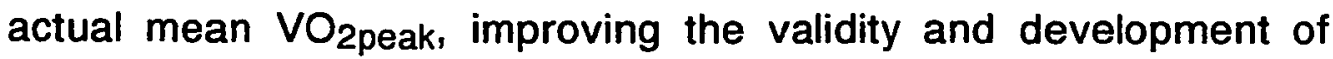
shallow water running field tests.

\section{Walking and Jogging Submaximal Field Tests}

Kline et al. (1987) estimated $\mathrm{VO}_{2 \text { peak }}$ from a one-mile track walk time, age, body weight, and gender. Subjects were 165 males and 178 females aged 39 to $69 \mathrm{yr}$. Each subject performed a maximal graded treadmill run to determine $\mathrm{VO}_{2 p e a k}$ and also walked a maximal one mile for time. Multiple regression analyses were calculated to predict $\mathrm{VO}_{2 \text { peak }}$ and revealed the following predictor variables: one-mile walk time, age, body weight, gender, and heart rate.

Kline et al. (1987) subsequently cross-validated the developed multiple regression equations on a second group of subjects $(N=169)$, and found a high correlation $(r=.92$ and $S E E=.355$ $\left.\mathrm{ml} \cdot \mathrm{kg}^{-1} \cdot \mathrm{min}^{-1}\right)$ between one-mile track walk time and $\mathrm{VO}_{2 \text { peak. }}$ Based on the results of the Kline et al. (1987) study, predictor variables which may be appropriate to include in the development of 
a regression equation to predict $\mathrm{VO}_{2 \text { peak }}$ from a field test are: test time, age, body weight, gender, and heart rate.

In a unique study by George et al. (1992), VO2peak was estimated from a submaximal one-mile track jog in fit college-age individuals. $\mathrm{VO}_{2 \text { peak }}$ was determined from a maximal graded treadmill run in 88 males and 61 females aged 18-29 yr. Subjects were randomly assigned to either a validation group, or a crossvalidation group. Through multiple regression analysis, $\mathrm{VO}_{2 p e a k}$ was predicted from the following predictor variables: jog time, body weight, gender, and exercise heart rate in the validation group $\left(r=.87, S E E=3.0 \mathrm{ml} \cdot \mathrm{kg}^{-1} \cdot \mathrm{min}^{-1}\right)$. Cross-validation revealed a strong correlation $\left(r=.84, S E E=3.2 \mathrm{ml} \cdot \mathrm{kg}^{-1} \cdot \mathrm{min}^{-1}\right)$ between the one-mile jog time and $\mathrm{VO}_{2 \text { peak. }}$ George et al. (1992) concluded that the one-mile track jog provides a valid, submaximal field test for estimating $\mathrm{VO}_{2 \text { peak }}$ in college-aged males and females. Based on the results of the George et al. (1992) study, variables which may be appropriate in the development of a regression equation to predict $\mathrm{VO}_{2 \text { peak }}$ from a field test are: test time, body weight, gender, and heart rate.

A. Jackson et al. (1992) investigated the validity and reliability of the one-mile walk as a field test of aerobic power for 21 male and 20 female young adults aged 19 to $32 \mathrm{yr}$. Subjects performed a maximal graded treadmill run to determine $\mathrm{VO}_{2 p e a k}$, and three trials of a maximum one-mile track walk. The alpha reliability estimates were $r=.96, .95$, and .95 for the three trials, 
respectively. The correlation between the third trial time and $\mathrm{VO}_{2 \text { peak }}$ was $r=-.57$; however, when the variables of one-mile walk time, body weight, gender, age, and post-walk heart rate were used to estimate $\mathrm{VO}_{2 \text { peak, }}$ the correlation improved to $r=.66$ (The correlation was reported as a positive coefficient, but was assumed to be an editorial error). Jackson et al. (1992) concluded that the one-mile walk is a very reliable, and moderately valid test of aerobic power in young women and men. The standard errors of estimate were not reported. Based on the results of the Jackson et al. (1992) study, the variables which may be appropriate in the development of regression equations to predict $\mathrm{VO}_{2 \text { peak }}$ from a field test are: test time, body weight, gender, age, and heart rate.

In a subsequent study by George et al. (1993), VO2peak was predicted from a submaximal one-mile track jog. A maximal graded treadmill run determined $V_{2} O_{2 p e a k}$ in all 149 fit subjects aged 18 to $29 \mathrm{yr}$. The one-mile track jog was performed by 106 subjects, and 96 subjects performed the 1.5 mile run for comparative purposes. When jog time, body weight, gender, and heart rate were used as variables to predict $\mathrm{VO}_{2 \text { peak }}$ from the one-mile track jog, the correlation was high $\left(r=.87\right.$, SEE $\left.=3.0 \mathrm{ml} \cdot \mathrm{kg}^{-1} \cdot \mathrm{min}^{-1}\right)$. When observed and estimated $\mathrm{VO}_{2 \text { peak }}$ values were cross-validated in the one-mile track jog the correlation was high as well $(r=.84$, SEE $=$ $\left.3.1 \mathrm{ml} \cdot \mathrm{kg}^{-1} \cdot \mathrm{min}^{-1}\right)$. Multiple regression analysis estimated $\mathrm{VO}_{2 \text { peak }}$ from the 1.5-mile run in the validation group $(n=49)$ which also

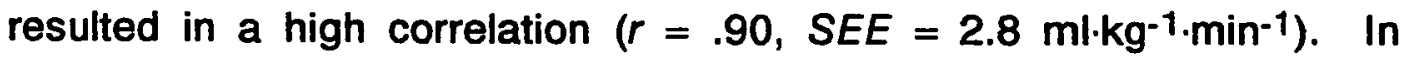


the cross-validation group ( $n=47$ ), run time, body weight, and gender were the identified predictor variables which resulted in $r=.82$ and the SEE $=3.9 \mathrm{ml} \cdot \mathrm{kg}^{-1} \cdot \mathrm{min}^{-1}$. George et al. (1993) concluded that a one-mile track jog can accurately predict $\mathrm{VO}_{2 p e a k}$ and is an alternative to maximal performance tests such as the 1.5-mile run. Based on the results of the George et al. (1993) study, variables which may be once again appropriate in the development of a regression equation to predict $\mathrm{VO}_{2 p e a k}$ from a field test are: test time, body weight, gender, and heart rate.

\section{Swimming Submaximal Field Tests}

Cooper (1977) proposed that the 12-min swim could be used as an alternative to the $12-\min$ run to classify $\mathrm{VO}_{2 p e a k}$. Cooper (1977) designed and modified fitness categories based on age groups from running data, but the validity of the classifications was not evaluated until recently.

A. Jackson, Jackson, and Frankiewicz (1979) investigated the construct and concurrent validity of a 12-min swim as a field test of swimming endurance in 42 young males experienced in aquatic skills who ranged from 18 to 27 years of age. The subjects were administered three tests: (a) a multistage endurance tethered swim test, (b) stroke count for two lengths, and (c) a 12-min swim for distance with total distance and distance covered each minute recorded for each subject. The authors concluded that 12-min swim performance was highly correlated $(r=.90)$ with tethered swim 
work capacity; however, swim $\mathrm{VO}_{2 p e a k}$ was not measured. The standard errors of estimate were not reported.

In an attempt to validate Cooper's proposal that the 12-min swim could be used as an alternative predictor of aerobic power, Conley et al. (1991) compared the validity of the 12-min swim with that of the 12-min run. The investigators also hypothesized that a more accurate estimate of tethered swim $\mathrm{VO}_{2 \text { peak }}$ would be obtained from the 12-min swim than from the 12-min run; and furthermore, a more accurate estimate of treadmill running $\mathrm{VO}_{2 \text { peak }}$ would be obtained from the 12-min run than from the 12-min swim. Subjects were 36 young men who were recreational swimmers. Subjects completed a 12-min run and swim for distance, as well as maximal swimming (tethered) and running (treadmill) tests. The distances completed were recorded to the nearest meter with a tape measure. Water temperature averaged $270 \pm .90 \mathrm{C}$. Correlation coefficients and SEE for predictions of tethered swim $\mathrm{VO}_{2 p e a k}$ from the 12-min swim $\left(r=.40\right.$, SEE $\left.=5.7 \mathrm{ml} \cdot \mathrm{kg} \cdot \mathrm{min}^{-1}\right)$ and $\cdot$ run $(r=.74$, SEE $=4.2$ $\left.\mathrm{ml} \cdot \mathrm{kg} \cdot \mathrm{min}^{-1}\right)$, and for prediction of treadmill run $\mathrm{VO}_{2 p e a k}$ from the 12-min swim $\left(r=.38, S E E=5.1 \mathrm{ml} \cdot \mathrm{kg} \cdot \mathrm{min}^{-1}\right)$ and run $(r=.88, S E E=$ $2.6 \mathrm{ml} \cdot \mathrm{kg} \cdot \mathrm{min}^{-1}$ ), indicated that the $12-\mathrm{min}$ run was a more accurate predictor of $\mathrm{VO}_{2 \text { peak }}$ than the 12-min swim test, regardless of whether $\mathrm{VO}_{2 \text { peak }}$ was measured during swimming or running. Conley et al. (1991) concluded that the 12-min swim has relatively low validity as a predictor of tethered swim $(r=.40)$ and treadmill run 
$(r=.38)$, and therefore should not be considered an equally valid alternative to the 12-min run in young male recreational swimmers.

In a more recent attempt to validate Cooper's proposal that the 12-min swim could be used as an alternative predictor of aerobic power, Conley et al. (1992) extended their earlier investigation of the validation of the 12-min swim as a field test of aerobic power. Methodology was similar to the previous study, however the subjects were 34 young women. Correlation coefficients and SEE for predictions of swimming $\mathrm{VO}_{2 \text { peak }}$ from the 12-min swim $(r=.42$, SEE $\left.=4.5 \mathrm{ml} \cdot \mathrm{kg} \cdot \mathrm{min}^{-1}\right)$ and run $\left(r=.58, S E E=4.1 \mathrm{ml} \cdot \mathrm{kg} \cdot \mathrm{min}^{-1}\right)$ and for predictions of treadmill run $\mathrm{VO}_{2 \text { peak }}$ from the 12-min swim $(r=.34$, $\left.S E E=6.0 \mathrm{ml} \cdot \mathrm{kg} \cdot \mathrm{min}^{-1}\right)$ and run $\left(r=.87, S E E=3.2 \mathrm{ml} \cdot \mathrm{kg} \cdot \mathrm{min}^{-1}\right)$, again indicated that the 12 -min run test was a better predictor of $\mathrm{VO}_{2 \text { peak }}$ than the 12-min swim test regardless of whether $\mathrm{VO}_{2 \text { peak }}$ was measured during swimming or running. Conley et al. (1992) revealed that some of the less skilled and less economical swimmers achieved a high $\mathrm{VO}_{2 \text { peak, }}$, but did not swim very far on the 12-min swim test. Accounting for differences in swimming skills, or economy, using the stroke-technique indicators did not sufficiently improve the accuracy of estimating $\mathrm{VO}_{2 \text { peak. }}$. Based on the results of both of the Conley et al. $(1991 ; 1992)$ studies, it may be appropriate to control for swimming skills in the development of a shallow water running field test by standardizing the arm movements in an effort to more acurately predict $\mathrm{VO}_{2 \text { peak. }}$ 
A Critical Evaluation of the Recently Developed 500-yd Shallow Water Run Field Test for the Prediction of Peak Aerobic Power

Kaminsky et al. (1993) were the first investigators to evaluate the 500-yd shallow water run field test for the prediction of peak aerobic power. The subjects included 15 men $(M \pm S D$ age $=19.8 \pm$ $1.1 \mathrm{yr})$ and 28 women $(M \pm S D$ age $=19.8 \pm 2.5 \mathrm{yr}$ ) of various fitness levels. Each subject ran four field tests: two 500-yd shallow water runs, and two 1.5 mile track runs. The first shallow water and track runs were used as trials to control for a learning effect. In addition to the field tests, each subject performed a maximal graded exercise test to determine $\mathrm{VO}_{\text {2peak. }}$. The mean $\pm S D \mathrm{VO}_{2 \text { peak }}$ values of the male and female subjects were $51.3 \pm 5.2 \mathrm{ml} \cdot \mathrm{kg}^{-1} \cdot \mathrm{min}^{-1}$ and 39.5 \pm 6.7 , respectively. Kaminsky et al. (1993) reported that treadmill $\mathrm{VO}_{2 \text { peak }}$ was more highly related to 1.5 -mile run time $(r=-.89)$ than the 500-yd shallow water run $(r=-.80)$. Multiple regression analyses revealed that the prediction of $\mathrm{VO}_{2 \text { peak }}$ from 500 -yd shallow water run time $\left(R=.79, S E E=5.14 \mathrm{ml} \cdot \mathrm{kg}^{-1} \cdot \mathrm{min}^{-1}\right)$ was improved when percent body fat $\left(R=.91\right.$, SEE $\left.=3.59 \mathrm{ml} \cdot \mathrm{kg}^{-1} \cdot \mathrm{min}^{-1}\right)$, or when percent body fat and height $(R=.93, S E E=3.19$ $\left.\mathrm{ml} \cdot \mathrm{kg}^{-1} \cdot \mathrm{min}^{-1}\right)$ were included in the prediction equations. Kaminsky et al. (1993) concluded that the 500-yd shallow water run provides an adequate prediction of aerobic power in men and women, especially when used with the descriptive measures of percent body fat and height. 
Although the methodology of the Kaminsky et al. (1993) study was generally well-designed, the study had several weaknesses which may limit its usefulness and application to other populations. The assessment of an individual's percent body fat in order to use the prediction equations developed by Kamisky et al. (1993) limits its practical utility in a large population. Prediction equations which use body weight rather than percent body fat would be easier to administer and may possibly be just as accurate, particularly since body weight and percent body fat had a similar relationship to the 500-yd SWR time ( $r=-.80$ and -.82 ) in the Kamisky et al. (1993) study.

Furthermore, the Kaminsky et al. (1993) study used a pool that sioped from a depth of $3.5 \mathrm{ft}$ to $5 \mathrm{ft}$, in which the subjects completed the shallow water run at a water depth midway between the navel and nipple line. Many shallow water runners use a pool with a constant water depth and, consequently, it is not always possible to select a water depth level that corresponds to the level of the water described in the Kaminsky et al. (1993) study. Therefore, shallow water runners who use a pool with a constant water depth may be unable to use the Kaminsky et al. (1993) equations. Perhaps height and/or leg length would be stronger predictor variables than previously identified in the equations used to predict $\mathrm{VO}_{2 \text { peak. }}$.

It should also be noted that the Kaminsky et al. (1993) study did not standardize the arm action during the shallow water run 
which could have affected the prediction equations as well. Likewise, it may be appropriate to standardize the turning style, and reduce the turning frequency. By requiring each subject to simply touch the wall with a single hand before turning, the turning style could be standardized. Subjects in the Kaminsky (1993) study had to turn at the pool wall 42 times during the SWR in an 11.5-yd pool; however, 23 turns could be eliminated by using a 25-yd pool. Subjects tested in a 25-yd pool would be required to turn 19 times, which perhaps would limit errors attributed to frequent turning.

Further, the Kaminsky et al. (1993) study used a rather homogenous population in terms of age and aerobic fitness level. Hence, the generalizability of the equations to a broader population may be limited. Finally, Kaminsky et al. (1993) did not crossvalidate the developed prediction equations on a separate sample of subjects. Therefore, to improve the generalizability of the Kaminsky et al. (1993) results, it would be appropriate to crossvalidate the equations on a separate sample of subjects and report the total error (mean difference plus SEE) for the prediction equations.

\section{Summary}

Distance runs and walks are widely used field tests because they are easy to administer and have high reliability and validity as indicators of treadmill $\mathrm{VO}_{2 p e a k}$ in comparison to submaximal swimming field tests which have low validity. In general, low fit subjects are less motivated than highly fit subjects to perform 
maximally on the field tests, which consequently lowers the validity coefficient. Yet, the inclusion of subjects with various fitness levels may improve the generalizability of the prediction equations to broad and diverse populations. The standard errors of estimate and/or total errors were not reported in many of the earlier studies; however, when included, they improved the interpretation of the regression equations accuracy and consequently, their usefulness in predicting VO2peak. Specifically, to improve the generalizability of the Kaminsky et al. (1993) results, it would be appropriate to crossvalidate the equations on a separate sample of subjects and report the total error (mean difference plus SEE) for the prediction equations.

The assessment of an individual's percent body fat in order to use the prediction equations developed by Kamisky et al. (1993) limits its practical utility in a large population; however, the inclusion of percent body fat as a predictor variable is necessary to cross-validate the original study. Prediction equations which used body weight rather than percent body fat would be easier to administer and possibly may be just as accurate.

Many shallow water runners use a pool with a constant water depth and, consequently, the Kaminsky et al. (1993) equation is limiting. Therefore, it is necessary to develop SWR field tests in a constant depth of water. Perhaps height and/or leg length would be stronger predictor variables than previously identified in the

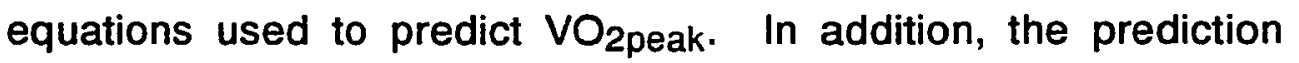


equations may have been affected by the lack of standardized arm action, turning style, and frequent turns performed during the shallow water run test. Consequently, arm action and turning style should be standardized in the development of future field tests, and turning frequency should be minimized.

Regression equations using multiple predictor variables may potentially result in higher correlation coefficients, and lower standard errors of estimate and total errors, than regression equations using a single predictor variable because they potentially take into consideration more factors affecting the criterion variable. Predictor variables which may be appropriate to consider in the development of regression equations to estimate aerobic power from shallow water running field tests are: test time, age, body weight, percent body fat, height, leg length, gender, heart rate, and possibly RPE. Caution should be considered in the selection of variables, as some may limit the practical utility of the submaximal test for a large group, such as an aquatic exercise class. 


\section{Chapter 3}

METHODS

Detailed in Chapter 3 is the descriptive information of the subjects, apparatus, procedures, design, and analysis of data for the purpose of presenting a logical format for testing the following relationships:

1. To what extent did the variables of age, gender, body weight, height, leg length, percent body fat, $\mathrm{VO}_{2 p e a k}, 300$-yd SWR time, 300-yd SWR heart rate, and 300-yd SWR rating of perceived exertion, 500-yd SWR time, 500-yd SWR heart rate, and 500-yd SWR rating of perceived exertion intercorrelate with one another?

2. To what extent did the predictor variables of age, gender, body weight, height, leg length, percent body fat, 300-yd SWR time, 300-yd SWR heart rate, and 300-yd SWR rating of perceived exertion combine to account for the variance in $\mathrm{VO}_{2 \text { peak? }}$

3. To what extent did the predictor variables of age, gender, body weight, height, leg length, percent body fat, 500-yd SWR time, 500-yd SWR heart rate, and 500-yd SWR rating of perceived exertion combine to account for the variance in $\mathrm{VO}_{2 \text { peak? }}$ ?

4. To what extent did the three equations developed by Kaminsky et al. (1993) predict $\mathrm{VO}_{2 \text { peak }}$ in the current study?

Subjects

The subjects in the study were 36 apparently healthy adult volunteers: 18 women and 18 men who ranged widely in age (21.25 to $48.42 \mathrm{yr})$. Apparently healthy subjects within this age range 
were generally considered representative of the population most likely to utilize the field tests. A physician was not required for either the SWR tests or the maximal GXT. Although the selected sample size $(N=36)$ was somewhat lower than the sample size used in the Kaminsky et al. (1993) study $(N=43)$, it did meet the minimal criterion of subjects per independent variable that has been recommended for regression analysis (A. S. Jackson, 1984).

\section{Apparatus}

Height and leg length were measured using a Broca ${ }^{\mathrm{TM}}$ plane and a wall scale; subjects were barefoot. Body weight was measured using a platform scale; subjects were again barefoot. Skinfold thicknesses were assessed using the Lange ${ }^{\mathrm{TM}}$ skinfold calipers. Peak oxygen uptake rate, or peak aerobic power, was determined from graded treadmill exercise testing (GXT) which utilized a MedGaphics Cardiopulmonary Exercise System CPX/D ${ }^{\mathrm{TM}}$. A Nihon Kohen Cardiofax $V^{T M}$ electrocardiograph was used to monitor heart rate and ECG rhythms continually during the GXT. During the GXT, all subjects wore running shoes, and shorts; the women wore a supportive bra and/or a t-shirt.

The 300-yd (12 laps) and 500-yd (20 laps) shallow water runs were timed in $106.68 \mathrm{~cm}$ (3.5 ft or $42 \mathrm{in.}$ ) deep water in a 25-yd swimming pool of $280 \mathrm{C}(820 \mathrm{~F})$. Borg's scale of perceived exertion, was used to measure RPE during the last $5 \mathrm{~s}$ of the SWR tests and each minute of the GXT; the numerical ratings on the scale ranged from very, very light (7) to very, very hard (19). Post-run heart rate 
was recorded upon completion of both SWR tests with a Polar Vantage $X L^{T M}$ heart rate monitor that each subject wore around the chest. Both SWR tests were performed barefoot in a swim suit.

Procedures

\section{Prior to Testing Methodology}

Each subject read and signed a consent form (Appendix A) and a health/medical history questionnaire (Appendix B), which was approved by the Human Subjects Institutional Review Board of San Jose State University, prior to testing. The order of testing was explained to each subject. Initially, subjects had laboratory assessments of body composition and size, and performed the maximal GXT. In an effort to control for learning effects, subjects practiced both the standardized SWR techinique and use of the RPE scale. Within a week after the laboratory/practice session, the subjects completed the testing by performing "best effort" 300 -yd and 500-yd shallow-water runs in a random order on different days.

\section{Testing Methodology}

The testing of the subjects was divided into the measurement of body composition (percent body fat) and size (height, leg length, and body weight), a maximal graded exercise test (GXT), and two different submaximal exercise test conditions (one 300-yd and one 500-yd SWR). Prior to the GXT, each subject was measured for body composition and size. The GXT was followed by a random order of the two submaximal exercise test conditions to control for a learning effect. 


\section{Body Composition and Size}

Body density was estimated from skinfold measurements using the equations published by Pollock et al. (1980). The Siri (1961) equation was used to calculate percent body fat from the estimated body density.

Height and leg length (measured from the greater trochanter to the floor) were measured with a wall scale utilizing a Broca ${ }^{\mathrm{TM}}$ plane. Height and leg length were expressed in centimeters $(\mathrm{cm})$. Leg length was averaged from the measurments of both right and left legs. Body weight was measured in kilograms $(\mathrm{kg})$ on a platform scale.

Maximal Graded Exercise Test

- Maximal graded exercise testing was conducted on each subject using the modified Bruce protocol (Bruce, Kusumi, \& Hosmer, 1973). The treadmill protocol began at $1.7 \mathrm{mph}$ and at a $10 \%$ grade for three minutes and continued with workload increases in speed and grade which approximated one metabolic equivalent (3.5 $\mathrm{ml}^{1} \mathrm{~kg}^{-1} \cdot \mathrm{min}^{-1)}$ every three minutes until voluntary exhaustion. This protocol was selected because Pollock et al. (1976) reported that $\mathrm{VO}_{2 \text { peak }}$ measured using the modified Bruce protocol was approximately $5 \%$ higher than $\mathrm{VO}_{2 \text { peak }}$ determined from a protocol using a graded treadmill walk. Hence, the modified Bruce protocol elicited a higher oxygen uptake rate which is more reflective of peak oxygen uptake rate. 
Subjects performed the GXT in a pair of socks and athletic shoes, as well as appropriate exercise clothing. Each subject was fitted with a mouthpiece and nose clip. The subjects inhaled room air continually throughout the maximal GXT. A Medgraphics Cardiopulmonary Exercise System CPX/D ${ }^{\mathrm{TM}}$ collected expired air samples breath-by-breath for the measurements of expired ventilation rate, oxygen uptake rate, carbon dioxide production rate, and $R$ values during the maximal GXT.

A Nihon Kohen Cardiofax $V^{T M}$ electrocardiograph was used to monitor heart rate and ECG rhythms continually during the GXT. The ECG lead placement during the maximal test consisted of five surface electrodes which were placed at the subject's right and left arms, right and left legs, and $v_{5}$. The leads monitored all cardiac electrical patterns and obtained heart rate during the last ten seconds of each minute of the test.

Peak oxygen uptake rate $\left(\mathrm{VO}_{2 p e a k}\right)$ was determined during the maximal GXT as the highest $\mathrm{VO}_{2}$ value obtained using the "mid 5 of 7" breath method described in the MedGraphics Cardiopulmonary Exercise Testing System (CPX/D) ${ }^{\mathrm{TM}}$ User's Manual (1993). All subjects met at least one of the following criteria indicating a maximal effort: (a) heart rate was within $10 \mathrm{~b} \cdot \mathrm{min}^{-1}$ of agepredicted maximal heart rate; (b) respiratory exchange ratio was above 1.0; and/or (c) $\mathrm{VO}_{2}$ reached a plateau $\left(<2.0 \mathrm{ml} \cdot \mathrm{kg}^{-1} \cdot \mathrm{min}^{-1}\right)$, 
or decreased with increasing workloads (McArdle et al., 1991). Peak heart rate (HRpeak) was determined as the highest heart rate reached during the maximal GXT.

The GXT test was terminated for any of the following reasons: (1) the subject requested to terminate the test, (2) failure of the heart rate to increase with increasing workloads, (3) pain or fatigue as indicated by decreased coordination or pallor, (4) abnormalities on the ECG reading, or (5) equipment failure (American College of Sports Medicine, 1991). For the purpose of this study, each subject voluntarily terminated the test after giving a "last-minute" signal. Shallow-Water Run Tests

Both submaximal exercise test conditions similarly adhered to the following methodologies. Prior to performing the shallow water runs, subjects were given instructions describing the RPE scale. Each subject wore a swim suit, and a Polar Vantage $X^{\top}{ }^{\top M}$ Heart Rate monitor which recorded heart rate (HR) every $5 \mathrm{~s}$ during and immediately following the shallow water runs. The average of the recorded heart rates during the first $15 \mathrm{~s}$ of recovery immediately following completion of the runs was identified as the 300-yd SWR and 500-yd SWR heart rates. Prior to the actual SWR tests, each subject was required to adequately warm-up by water walking and jogging for two to three minutes followed by stretching. The SWR tests began with the subject's hand touching the pool wall.

Each subject was instructed to run forward in the pool at as fast of a pace as possible for 12- and 20-laps to complete the 
300-yd and 500-yd SWR, respectively. Throughout the test, each runner remained in a designated marked "lane" at each end of the pool. Each subject was tested individually. During the SWR, the subjects were given verbal encouragement to do the best they could. One lap was designated at each turn. Subjects were required to touch the wall with one hand before the lap was counted. A person designated as a lap counter sat at the end of the pool revealing and recording the number of laps each subject completed. In addition, the lap counter recorded RPE and the time at completion of every two laps. The RPE values that were recorded during the last $5 \mathrm{~s}$ of each SWR was identified as either the 300-yd SWR RPE, or 500-yd SWR RPE.

The subjects' arm movements were similar to the arm action used to swim the front crawl. Specifically, the "recovery" portion of the armstroke was performed through the air; and, the "propulsive" phase was performed as the fingertips entered the water and continued to sweep the submerged hand and arm past the hips. The level that the arm was submerged depended on the subject's height, motivation, need for balance, and possible swimming skills. In fact, a "feel for the water" may have brought an element of balance necessary to water running, without significantly affecting the skill component in swimming field tests as mentioned by Conley et al. (1992).

The time of the SWR was recorded by a designated investigator in the study at the completion of 300-yd (12 laps) and 500-yd (20 
laps) in minutes (min) and seconds (s) from the time the subject left the pool wall, until the wall of the final lap was touched with one hand. A run was terminated early if a subject exhibited dizziness, pain, or fatigue as indicated by decreased coordination or pallor.

Analysis of Data

Descriptive statistics, means and standard deviations, were used to describe the characteristics of age, body weight, height, leg

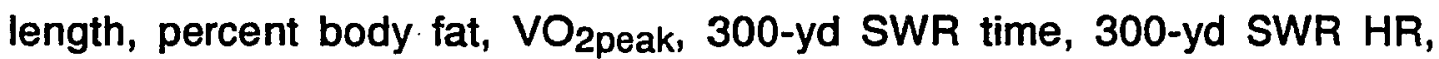
300-yd SWR RPE, 500-yd SWR time, 500-yd SWR HR, and 500-yd SWR RPE in the male and female subjects, as well as the total group of subjects. Independent $t$-tests were used to compare the characteristics of the male and female data. For the data of the total group, Pearson product-moment correlations $(r)$ were used to examine the relationships between the descriptive characteristics of age, gender, body weight, height, leg length, percent body fat, VO ${ }_{2 p e a k}, 300$-yd SWR time, 300-yd SWR HR, 300-yd SWR RPE, 500-yd SWR time, 500-yd SWR HR, and 500-yd SWR RPE. Stepwise multiple regression analyses were used to develop regression equations predicting the criterion variable of $\mathrm{VO}_{2 \text { peak }}$ from the predictor variables of: age, gender, body weight, height, leg length, percent body fat, 300-yd SWR time, 300-yd SWR HR, 300-yd SWR RPE, 500-yd SWR time, 500-yd SWR HR, and 500-yd SWR RPE. In order to develop equations that could be used in swimming pools that differed from the $106.68 \mathrm{~cm}$ (i.e., 42 in.) water depth used in the current study, forward multiple regression analyses were 
calculated. Forward multiple regression analyses were used to add the calculated variable of height/water depth into each of the developed equations from stepwise multiple regression analyses. In addition to the calculation of multiple correlation coefficients $(R)$, standard errors of estimate $\left(S E E=S D_{y} \sqrt{1-R^{2}}\right)$ were also calculated from the multiple regression analyses.

Cross-validation of the previously developed equations by Kaminsky et al. (1993) for predicting $\mathrm{VO}_{2 \text { peak }}$ from 500-yd SWR time involved the calculation of the mean differences and correlation coefficients $(r)$ between actual $\mathrm{VO}_{2 \text { peak }}$ and predicted $\mathrm{VO}_{2 \text { peak. The }}$ mean difference was calculated by subtracting the predicted peak oxygen uptake rate estimated from the regression equations from the actual peak oxygen uptake rate measured during the maximal graded exercise test. In addition, cross-validation of the previously developed equations involved the calculation of the standard errors of estimate $\left(S E E=S D_{y} \sqrt{1-r^{2}}\right)$, and total error [total error = $\sqrt{\left.\left(\text { Predicted } \mathrm{VO}_{2 \text { peak }}-\mathrm{VO}_{2 \text { peak }}\right)^{2 / N}\right]}$.

Interpretations of the 300-yd and 500-yd SWR tests along with the other variables as valid predictors of $\mathrm{VO}_{2 \text { peak }}$ were based on the evaluations of Pearson product-moment correlation coefficients, multiple regression correlation coefficients, standard errors of estimate, and total errors. Correlation coefficents of $\geq .80$ between the measures of the predictor and criterion variables essentially meets the minimum criterion for establishing validity on tests of physical fitness (Baumgartner \& Jackson, 1991; Bruce, 
Kusumi, \& Hosmer, 1973). The alpha level for statistical significance was $p \leq .05$. 


\section{Chapter 4}

\section{RESULTS}

The first section in Chapter 4 contains the data analyses of the descriptive characteristics and gender comparisons, followed by a brief summary and discussion. Then, the descriptive characteristics and gender comparisons were contrasted with the results of the Kaminsky et al. (1993) study. The second section includes the data analysis of the correlation coefficients for the descriptive characteristics of subjects, succeeded by a short summary and discussion. Then, the correlation coefficients for the descriptive characteristics of subjects were again compared with the results of the Kaminsky et al. (1993) study. The third section includes the multiple regression analyses, followed by a brief summary and discussion. The fourth and final section in Chapter Four contains the cross-validation of the multiple regression equations previously developed by Kaminsky et al. (1993) for predicting $\mathrm{VO}_{2 \text { peak }}$ from 500 -yd SWR time, followed once again by a short summary and discussion.

Descriptive Characteristics and Gender Comparisons Analysis of the Descriptive Characteristics and Gender Comparisons

The descriptive characteristics, means and standard deviations of the 36 subjects, were calculated for the 18 male and 18 female subjects, as well as for the total group of 36 subjects. The descriptive statistics of age, body weight, height, leg length,

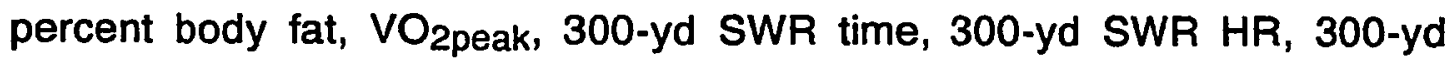


SWR RPE, 500-yd SWR time, 500-yd SWR HR, and 500-yd SWR RPE are summarized in Table 1. The mean $(M \pm S D)$ age for the total group was $27.95 \pm 6.43 \mathrm{yr}$. Mean body weight for the overall group was $70.07 \pm 14.23 \mathrm{~kg}$. Subjects height averaged $170.15 \pm 9.29 \mathrm{~cm}$ with a mean leg length of $87.48 \pm 5.46 \mathrm{~cm}$. The mean percent body

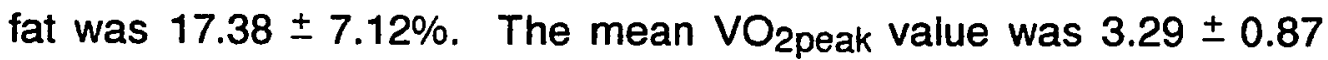
$L \cdot \min ^{-1}$, or expressed relative to body weight, $46.88 \pm 7.76$ $\mathrm{ml} \cdot \mathrm{kg}^{-1} \cdot \mathrm{min}^{-1}$. As expected, the mean time in the 300-yd SWR $(4.88 \pm 0.66 \mathrm{~min})$ was somewhat faster than the mean time in the 500 -yd SWR time $(8.38 \pm 1.10 \mathrm{~min})$; and, the mean heart rate value in the 300-yd SWR $\left(178.12 \pm 11.90 \mathrm{~b} \cdot \mathrm{min}^{-1}\right)$ was somewhat lower than the HR values in the 500-yd SWR (180.52 $\left.\pm 8.84 \mathrm{~b} \cdot \mathrm{min}^{-1}\right)$. Likewise, the mean 300-yd SWR RPE $(17.47 \pm 1.94)$ was somewhat lower than the 500-yd SWR RPE (18.12 \pm 1.98$)$.

Independent $t$-tests were calculated to compare the previously identified descriptive characteristics of female and male data and are presented in Table 1. Significant differences $(p \leq .05)$ were revealed between the mean female and male data in the variables of body weight $(61.17 \pm 11.38$ vs $78.98 \pm 10.94 \mathrm{~kg})$, height $(166.62$ \pm 5.72 vs $177.69 \pm 4.98 \mathrm{~cm})$, leg length $(83.83 \pm 4.42$ vs $91.12 \pm 3.72$ $\mathrm{cm})$, percent body fat $(22.44 \pm 5.55$ vs $12.33 \pm 4.43 \%)$, VO 2 peak $(2.58$ \pm 0.32 vs $\left.4.00 \pm 0.63 \mathrm{~L} \cdot \mathrm{min}^{-1}\right), 300$-yd SWR time $(5.34 \pm 0.57$ vs 4.41 $\pm 0.32 \mathrm{~min}), 300$-yd SWR HP $(173.68 \pm 11.40$ vs $182.57 \pm 10.96$ b. $\left.\mathrm{min}^{-1}\right)$, and 500 -yd SWR time (9.16 \pm 0.89 vs $\left.7.59 \pm 0.63 \mathrm{~min}\right)$. 


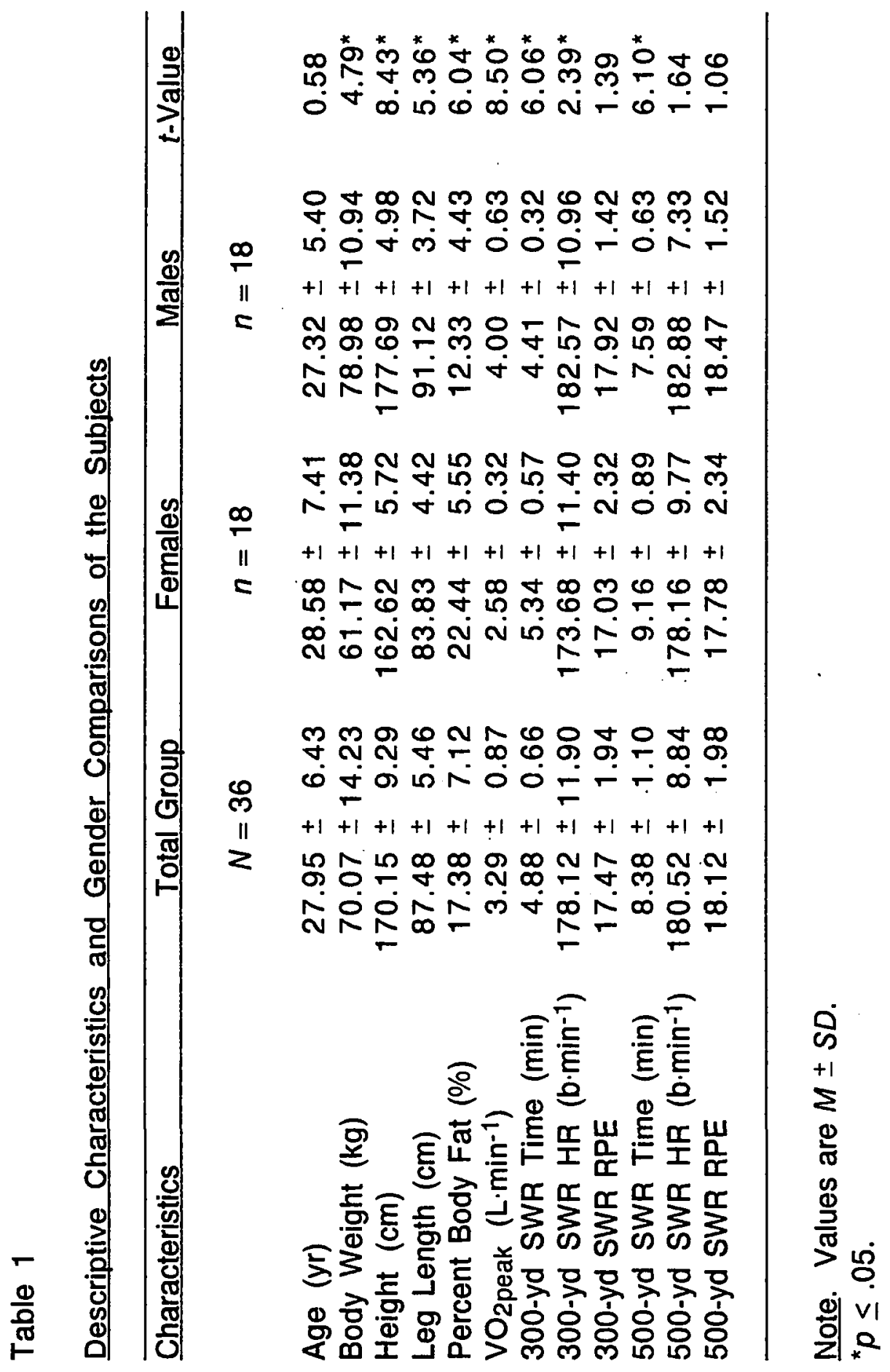


In contrast, no significant differences were revealed between the female and male mean data in the variables of age $(28.58 \pm 7.41$ vs $27.32 \pm 5.40 \mathrm{yr}), 300$-yd SWR RPE (17.03 \pm 2.32 vs $17.92 \pm 1.42)$, 500-yd SWR RPE (17.78 \pm 2.34 vs $18.47 \pm 1.52)$, and 500-yd SWR HR $\left(178.16 \pm 9.77\right.$ vs $\left.182.88 \pm 7.33 \mathrm{~b} \cdot \mathrm{min}^{-1}\right)$.

Summary and Discussion of the Descriptive Characteristics and

\section{Gender Comparisons}

Subjects in the study were generally considered young adults $(27.95 \pm 6.43 \mathrm{yr})$; however, the ages ranged widely from 21.25 to $48.42 \mathrm{yr}$. Subjects' percent body fat levels were evaluated by the classification standards described by "Body Composition: A Round Table" (1986). In general, the mean percent body fat of the females $(22.44 \pm 5.55 \%)$ was considered to be in the range classified as either optimal fitness (16-25\%), or health (18-30\%); however, the lower, average percent body fat of the males $(12.33 \pm 4.43 \%)$ fell within ranges classified as either most athletes $(5-13 \%)$, or optimal fitness $(12-18 \%)$. The ranges of percent body fat within each gender were again varied as percent body fat levels for the females and males ranged from $15.96-36.71 \%$ and $5.82-22.57 \%$, respectively.

The mean value of aerobic power $\left(\mathrm{VO}_{2 \text { peak }}\right)$ that was achieved by each gender during the graded exercise test was classified according to standards set by Heyward (1984). Based on the mean age of each gender, the mean female $\mathrm{VO}_{2 \text { peak }}$ value $(42.88 \pm 6.10$ $\left.\mathrm{ml}^{\prime} \mathrm{kg}^{-1} \cdot \mathrm{min}^{-1}\right)$ was classified as good (43-52 $\left.\mathrm{ml} \cdot \mathrm{kg}^{-1} \cdot \mathrm{min}^{-1}\right)$; however, the even though the mean male $\mathrm{VO}_{2 \text { peak }}$ value $(50.89 \pm 6.85$ 
$\mathrm{ml} \cdot \mathrm{kg}^{-1} \cdot \mathrm{min}^{-1}$ ) was somewhat higher than that of the females, the

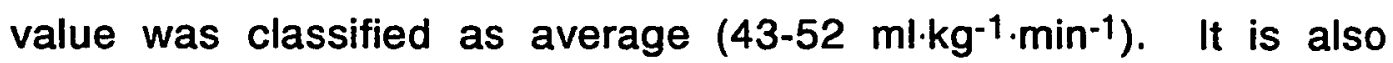
interesting to note that the ranges of $\mathrm{VO}_{2 \text { peak }}$ values within each gender were diverse for both females (32.1 to $\left.51.3 \mathrm{ml} \cdot \mathrm{kg}^{-1} \cdot \mathrm{min}^{-1}\right)$ and males (36.4 to $\left.58.8 \mathrm{ml} \cdot \mathrm{kg}^{-1} \cdot \mathrm{min}^{-1}\right)$.

As previously discussed, the mean times for the total group of subjects in the 300-yd and 500-yd SWR were $4.88 \pm 0.66$ and 8.38 $\pm 1.10 \mathrm{~min}$, respectively. The mean 500-yd SWR times for each gender were compared to the classification standards published by Robbins et al. (1991). The mean female 500-yd SWR time (9.16 \pm $0.89 \mathrm{~min}$ ) was classified within the average category (8.60-9.42 $\mathrm{min})$; however, the males mean 500-yd SWR time $(7.59 \pm 0.63 \mathrm{~min})$ was classified within the poor category (7.58-7.85 $\mathrm{min})$. Interestingly, there were conflicts in the classifications of fitness levels in the males and females when the average 500-yd SWR time and $\mathrm{VO}_{2 \text { peak }}$ value were compared to the normative data published by Robbins et al. (1991) and Heyward (1984). The high correlation $(r=-.87)$ found in the current study between the 500-yd SWR times and the $\mathrm{VO}_{2 \text { peak }}$ values suggests that the classifications of fitness levels be somewhat similar, when, in fact, the rankings were quite different within each gender. Specifically, the mean female $\mathrm{VO}_{2 \text { peak }}$ value ranked good; yet, the mean female 500-yd SWR time ranked average. Likewise, the mean male $\mathrm{VO}_{2 p e a k}$ value ranked average; yet, the mean 500-yd SWR time ranked poor. 
In addition to the contradictory fitness classification standards noted within each gender, the rankings were also contradictory between genders. Specifically, the average female SWR time was significantly slower than the male SWR time (9.16 \pm 0.89 vs $7.59 \pm 0.63 \mathrm{~min}$ ); yet, the average female SWR time was classified as average. Rather astonishingly, the male SWR time was classified as poor. The discrepancies found both within and between the gender comparisons of fitness categories, based on SWR times and $\mathrm{VO}_{2 \text { peak }}$ values, suggests that the norms established by Robbins et al. (1991) for the 500-yd SWR may not be valid, and perhaps should not be used until further research is completed.

Finally, it has been noted by the American College of Sports Medicine (1991) that the RPE numeric scale correlates closely with land-based heart rate. It is interesting that the mean $H R$ values for the 300-yd (178.12 $\left.\pm 11.90 \mathrm{~b} \cdot \mathrm{min}^{-1}\right)$ and 500-yd SWR (180.52 \pm 8.84 b. $\min ^{-1}$ ) corresponded closely to the average RPE values for the 300-yd SWR (17.47 \pm 1.94$)$ and the 500-yd SWR (18.12 \pm 1.98 ).

A Comparison of the Descriptive Characteristics and Gender Comparisons

In order for the equations developed by Kaminsky et al. (1993) to be valid in other populations and pools, the results of the current study were compared with the results of the Kaminsky et al. (1993) study. Differences were revealed between the subjects in both studies, specifically in the variables of age (females $=19.8$ 
\pm 2.5 vs $28.58 \pm 7.41 \mathrm{yr}$; males $=19.8 \pm 1.1$ vs $27.32 \pm 5.40 \mathrm{yr}$ ) and $\mathrm{VO}_{2 \text { peak }}$ (females $=39.5 \pm 6.7$ vs $42.88 \pm 6.10 \mathrm{ml} \cdot \mathrm{kg}^{-1} \cdot \mathrm{min}^{-1}$; males $=51.3 \pm 5.2$ vs $50.89 \pm 6.85 \mathrm{ml} \cdot \mathrm{kg}^{-1} \cdot \mathrm{min}^{-1}$ ). Simply put, both the females and males in the current study were slightly older than the subjects used in the Kaminsky et al. (1993) study. The older and wider age range in the current study, may make the equations more useful to a broader population than the younger sample used in the Kaminsky et al. (1993) study. The females in the current study had somewhat higher aerobic power than the females in the Kaminsky et al. (1993) study; however, the males in both studies had similar levels of aerobic power.

Additional similarities were found between subjects in the Kaminsky et al. (1993) study and the sample used in the current study; specifically in the variables of percent body fat (females $=24.9 \pm 6.8$ vs $22.44 \pm 5.55 \%$; males $=12.9 \pm 5.9$ vs $12.33 \pm 4.43 \%$ ); weight (females $=62.1 \pm 16.1$ vs $61.17 \pm 11.38 \mathrm{~kg}$; males $=77.5$ \pm 9.3 vs $78.98 \pm 10.94$ ); height (females $=163.8 \pm 8.9$ vs 162.62 $\pm 5.72 \mathrm{~cm}$; males $=179.6 \pm 6.1$ vs $177.69 \pm 4.98 \mathrm{~cm}$ ); and leg length (males $=91.2 \pm 3.8$ vs $91.12 \pm 3.72 \mathrm{~cm}$ ). There was a large difference, however, between the longer, average female leg length in the Kaminsky et al. (1993) study compared to the shorter leg length measured in the current study $(91.2 \pm 5.1$ vs $83.83 \pm 4.42 \mathrm{~cm})$. In the Kaminsky et al. (1993) study, it was unusual that the female average leg length was similar to the male average leg length (91.2 
\pm 5.1 vs $91.2 \pm 3.8 \mathrm{~cm}) ;$ and yet, the average female height was shorter than the male height $(163.8 \pm 8.9$ vs $179.6 \pm 6.1 \mathrm{~cm})$. The discrepancies in a similar leg length yet shorter height in the female values reported in the Kaminsky et al. (1993) study contradicts the high correlation between leg length and height $(r=.87)$ found in the current study. Apparently, there may be an error in the reported female leg length in the Kaminsky et al. (1993) study. It is notable, that the investigator in the current study found locating the greater trochanter generally difficult, especially in the female subjects. Both left and right leg lengths were measured, and when a discrepancy of more than $1 \mathrm{~cm}$ was found, the measurements were repeated, perhaps controlling for some error. Therefore, it is recommended that both leg lengths be carefully measured when using equations which include leg length.

\section{Correlation Coefficients}

for the Descriptive Characteristics of the Subjects Analysis of the Correlation Coefficients for the Descriptive Characteristics of the Subjects

For the data of the total group, Pearson product-moment correlations were calculated to examine the relationships between the descriptive characteristics of age, body weight, height, leg length, percent body fat, $\mathrm{VO}_{2 p e a k}$ 300-yd SWR time, 300-yd SWR HR, 300-yd SWR RPE, 500-yd SWR time, 500-yd SWR HR, and 500-yd SWR RPE. A matrix of the correlation coefficients for the descriptive characteristics of the subjects is presented in Table 2. 


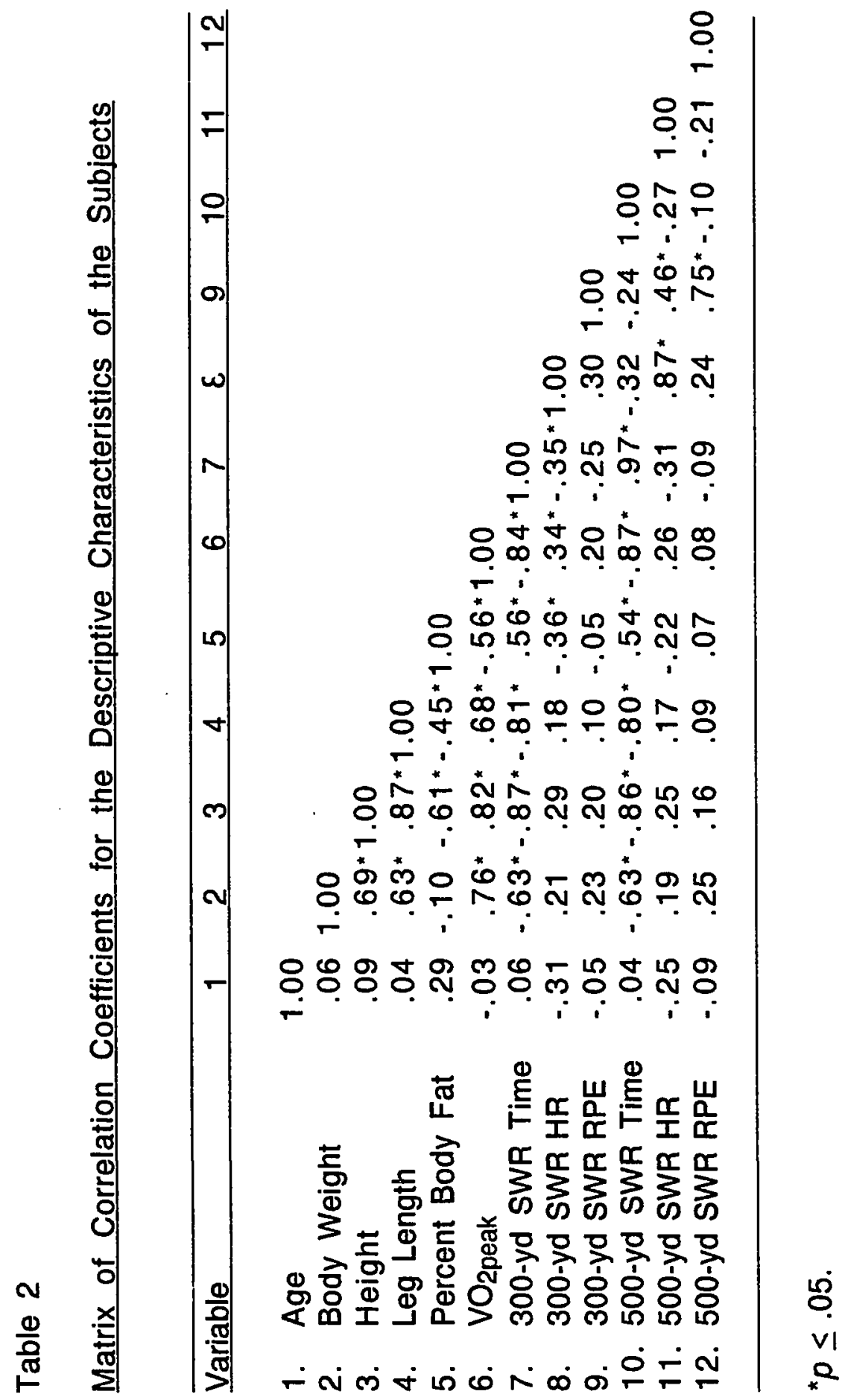


Of interest, were significant $(p \leq .05)$ correlations revealed between $\mathrm{VO}_{2 \text { peak }}$ and the 300-yd SWR time $(r=-.84)$ and 500-yd SWR time $(r=-.87)$. Also, there was a significant correlation between $V_{2 \text { peak }}$ and the 300-yd SWR HR ( $\left.r=.34\right)$; and, a nonsignificant relationship between $\mathrm{VO}_{2 \text { peak }}$ and the 500-yd SWR HR $(r=.26)$. Also, $\mathrm{VO}_{2 p e a k}$ was significantly correlated to percent body fat $(r=-.56)$, leg length $(r=.68)$, body weight $(r=.76)$, and height $(r=.82)$.

As previously noted, the 300-yd and 500-yd SWR times correlated highly to $\mathrm{VO}_{2 \text { peak }}(r=-.84$ and -.87 , respectively). Also, the 300-yd and 500-yd SWR times had high correlations with height ( $r=-.87$ and -.86 , respectively) and leg length $(r=-.81$ and -.80 , respectively). The 300-yd and 500-yd SWR times had moderate correlations with body weight $(r=-.63$ and -.63 , respectively) and percent body fat ( $r=.56$ and .54 , respectively). The highest correlation coefficient was between both of the SWR times $(r=.97)$. Summary and Discussion of the Correlation Coefficients for the Descriptive Characteristics of the Subjects

The correlations between $\mathrm{VO}_{2 p e a k}$ and the 300-yd $(r=-.84)$ and 500-yd $(r=-.87)$ SWR times meets the minimum criterion of $r=.80$ for establishing validity on tests of physical fitness (Baumgartner \& Jackson, 1991; Bruce et al., 1973). Therefore, both the 300-yd and 500-yd SWR are valid field tests for the prediction of aerobic power in young adults. Consequently, both SWR field tests should be considered valid alternatives to the 12-min swim (Conley et al., 
1991; Conley et al., 1992) for accurately predicting aerobic power in young adults.

The significant, yet weak correlation between $\mathrm{VO}_{2 \text { peak }}$ and the 300-yd SWR HR $(r=.34)$, as well as the lack of a relationship between $\mathrm{VO}_{2 \text { peak }}$ and the 500-yd SWR HR $(r=.26)$, were perhaps attributed to individual differences, and/or the unique heart rate responses during water exercise compared to land-based exercise (i.e., such as a nonlinear relationship between heart rate and oxygen uptake rate). Interestingly, Kaminsky et al. (1993) also found a weak relationship between $\mathrm{VO}_{2 p e a k}$ and 500 -yd $\mathrm{HR}(r=.06)$. The lack of strong correlations in both studies between both the 300-yd and 500-yd SWR HR and $\mathrm{VO}_{2 \text { peak }}$ suggests that postexercise heart rate may not be a valid method to predict $\mathrm{VO}_{2 \text { peak }}$ during SWR field tests.

In contrast, the 300-yd and 500-yd SWR times had high correlations with height ( $r=-.87$ and -.86 , respectively) and leg length ( $r=-.81$ and -.80 , respectively); and as previously mentioned, height was also highly correlated to leg length $(r=.87)$. The strong correlations suggest that leg length and/or height should be variables to consider when SWR testing. The shorter stature subjects appeared to generally encounter more water resistance than the subjects with greater heights/leg lengths. The 300-yd and 500-yd SWR times were moderately correlated with body weight $(r=-.63)$. Again, larger and heavier subjects generally tended to encounter more water resistance than smaller and lighter subjects during the SWR tests. Therefore, in addition to height and leg 
length, body weight is also an important variable to account for when SWR testing.

Of further interest was the strongest correlation found between the 300-yd and 500-yd SWR times $(r=.97)$. The extremely strong relationship between the two SWR tests indicated that the 300-yd SWR test can be another valid, yet shorter, more practical, and safer field test than the 500-yd SWR test to predict aerobic power in men and women.

\section{A Comparison of the Correlation Coefficients Previously Developed} in the Kaminsky et al. (1993) Study

The correlation between $\mathrm{VO}_{2 \text { peak }}$ and the 500-yd SWR time in the current study $(r=-.87)$ was somewhat stronger than the correlation in the Kaminsky et al. (1993) study $(r=-.80)$. As previously stated, both correlations meet the minimum criterion of .80 for establishing validity on tests of physical fitness (Baumgartner \& Jackson, 1991; Bruce et al., 1973); however, the stronger correlation found in the current study may be due to several factors.

First, the Kaminsky et al. (1993) study did not standardize for a specified arm action during the SWR tests. The current study required a front crawl-like motion of the arms which tended to provide the subjects with a sense of timing and balance, possibly improving the technique of shallow water running.

Secondly, the Kaminsky et al. (1993) study utilized a pool (35 ft per width) in which subjects had to run 43 widths to complete 
500-yd; however, in the current study, a 25-yd pool was available which required 20 widths of shallow water running. Fewer than half the number of turns (19 vs 42 ) were performed by the subjects in the current study compared to the Kaminsky et al. (1993) study, which consequently may have controlled for a substantial amount of error due to turning frequency. Also, the current study required the subjects to touch the pool wall with one hand, prior to turning. Perhaps detailed instructions on turning style should be advised and practiced prior to using the SWR field tests.

Thirdly, the Kaminsky et al. (1993) study conducted the 500-yd SWR tests in a pool that sloped from 3.5 to $5 \mathrm{ft}$ in water depth in which the water depth changed from between the nipple line and the navel of each subject. The subjects in the current study ran in a constant water depth of $106.68 \mathrm{~cm} \cdot(3.5 \mathrm{ft}$ or $42 \mathrm{in}$.) for the entire 500-yd; thus, the water line remained similar upon each subject, but was unique for each subject based on their height and/or leg length. Each subject in the current study most likely encountered a somewhat similar amount of water resistance or buoyancy throughout the entire 500-yd, and hence may have limited errors associated with height and/or body weight variances. In fact, interestingly, the Kaminsky et al. (1993) study reported a lower, yet significant, correlation between 500-yd SWR time and height than in the current study ( $r=-.64$ vs $r=-.86$ ), and also, a lower, nonsignificant correlation between 500-yd SWR time and body weight $(r=-.08$ vs $r=-.63)$. Therefore, both studies support the 
consideration of height as an important variable when SWR testing; however, contrary to the findings of Kaminsky et al. (1993), body weight also appears to be an important variable which needs to be accounted for when SWR testing.

Although the significant correlations between percent body fat and 500-yd SWR time in the Kaminsky et al. (1993) study $(r=.57)$ and in this study $(r=.54)$ were similar, stepwise multiple regression analyses loaded percent body fat as a significant predictor in the Kaminsky et al. (1993) study; however, percent body fat was not selected as a predictor variable in the set of equations utilizing 500-yd SWR times to predict $\mathrm{VO}_{2 \text { peak }}$ in this study. Therefore, contrary to the findings of Kaminsky et al. (1993), percent body fat does not appear to be an important variable which needs to be accounted for when SWR testing.

In summary, several factors were discussed that may have influenced the somewhat stronger correlation between $\mathrm{VO}_{2 p e a k}$ and 500-yd SWR time in the current study compared to the correlation in the Kaminsky et al. (1993) study. The influential factors identified were the specified arm action, turning style and frequency, and constant water depth.

\section{Multiple Regression Analyses}

\section{Multiple Regression Analyses}

Stepwise multiple regression analyses were used to develop regression equations predicting the criterion variable $\mathrm{VO}_{2 p e a k}$ from the predictor variables of: age, gender, body weight, height, leg 
length, percent body fat, 300-yd SWR time, 300-yd SWR HR, 300-yd SWR RPE, 500-yd SWR time, 500-yd SWR HR, and 500-yd SWR RPE. To develop equations that could be used in pools that differed from the water depth used in the current study, forward multiple regression analyses were calculated which were used to add the calculated variable of height/water depth into each of the developed equations from stepwise multiple regression analyses. In addition to the calculation of multiple correlation coefficients $(R)$, standard errors of estimate were calculated from the multiple regression equations.

The multiple regression equations for predicting $\mathrm{VO}_{2 \text { peak }}$ from the 300-yd SWR time are presented in Table 3. Interestingly, the basic Equation 1 produced a high correlation $(R=.840 ;$ SEE $=0.480$ $L \cdot \mathrm{min}^{-1}$ ) for predicting $\mathrm{VO}_{2 \text { peak }}$ from the 300-yd SWR time, indicating that the 300-yd SWR time accounted for $70.6 \%$ of the variance in $\mathrm{VO}_{2 \text { peak. }}$ The highest correlation $(R=.920 ; S E E=0.364$ $\left.L \cdot \min ^{-1}\right)$ was achieved in Equation 6 when the variables of gender, body weight, and height/water depth were included with the 300-yd SWR time. Hence, gender, body weight, height/water depth, and 300yd SWR time combined to account for $84.6 \%$ of the variance in $\mathrm{VO}_{2 \text { peak. }}$

The multiple regression equations for predicting $\mathrm{VO}_{2 \text { peak }}$ from the 500-yd SWR time are presented in Table 4. Again, a high correlation $\left(R=.865 ; S E E=0.443 \mathrm{~L} \cdot \mathrm{min}^{-1}\right)$ existed in the basic Equation 1 for predicting $\mathrm{VO}_{2 \text { peak }}$ from the 500-yd SWR time, 


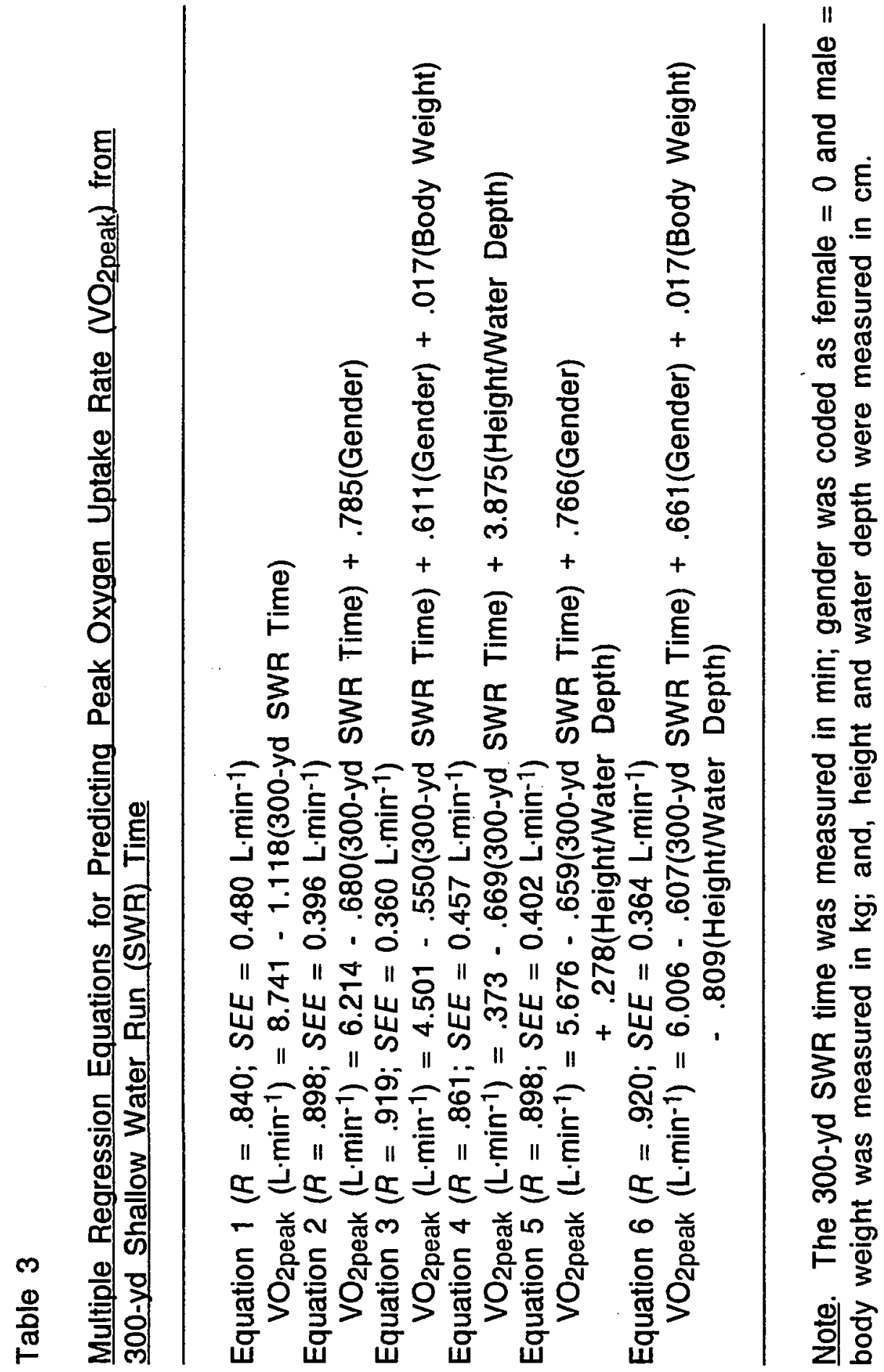



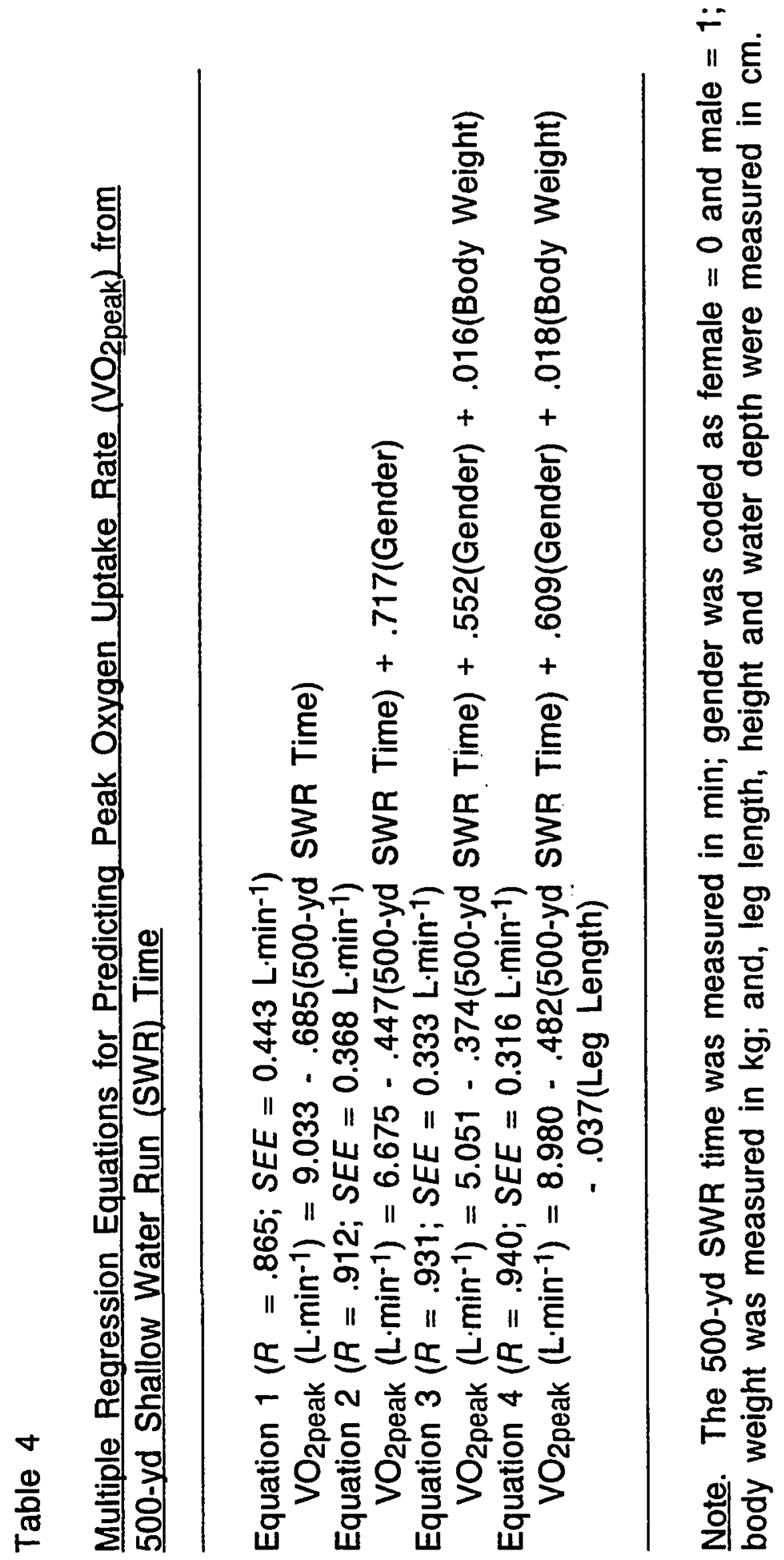


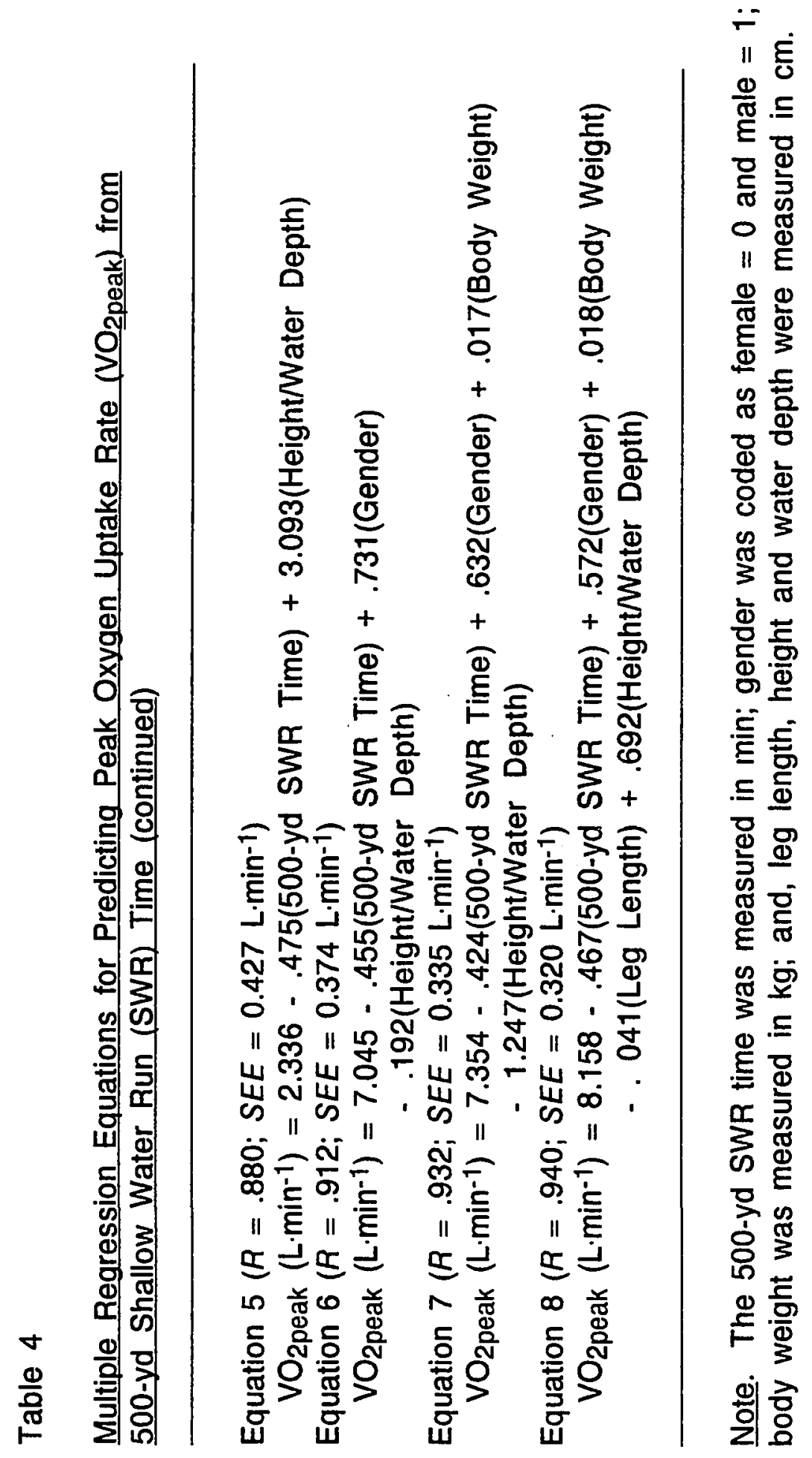


revealing that the 500-yd SWR time accounted for $74.8 \%$ of the

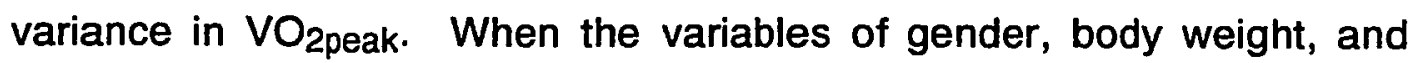
leg length were included with the 500-yd SWR time, the highest correlation and lowest SEE were achieved in Equation $4(R=.940$; $\left.S E E=0.316 L \cdot \mathrm{min}^{-1}\right)$. Thus, gender, body weight, leg length, and 500 -yd SWR time combined to account for $88.4 \%$ of the variance in $\mathrm{VO}_{2 p e a k}$. In Equation 8, the addition of height/water depth to the variables of gender, body weight, and leg length for predicting $\mathrm{VO}_{2 \text { peak }}$ resulted in a $R=.940$ and SEE $=.320 \mathrm{~L} \cdot \mathrm{min}^{-1}$. Hence, height/water depth, gender, body weight, leg length, and 500-yd SWR time combined to account for $88.4 \%$ of the variance in $\mathrm{VO}_{2 \text { peak. }}$ Summary and Discussion of the Multiple Regression Analyses

A total of six equations were developed for predicting $\mathrm{VO}_{2 \text { peak }}$ from a given 300-yd SWR time; eight equations were developed for predicting $\mathrm{VO}_{2 \text { peak }}$ from a given 500 -yd $\mathrm{SWR}$ time. From a practical standpoint, the addition of the calculated variable of height/water depth into a developed equation may increase the usefulness of the equations in swimming pools that differ from the $106.68 \mathrm{~cm}(3.5 \mathrm{ft}$ or 42 in.) water depth used in the current study.

Similar to the results of previous research (e.g., George et al., 1992, 1993; A. Jackson et al., 1992; Kline et al., 1987), test time was identified as an appropriate variable in the development of regression equations to predict $\mathrm{VO}_{2 \text { peak }}$ in the current study. In fact, the most simple equations in the current study required either a specific $300-y d$ or $500-y d$ SWR time, and produced high correlations 
and reasonable standard errors of estimate for predicting $\mathrm{VO}_{2 \text { peak }}$ from both the 300-yd SWR $\left(R=.840 ;\right.$ SEE $\left.=0.480 \mathrm{~L} \cdot \mathrm{min}^{-1}\right)$ and 500yd SWR $\left(R=.865 ; S E E=0.443 L \cdot m^{-1}\right)$ times. In other words, the 500 -yd SWR time accounted for slightly more (4.2\%) of the variance in $\mathrm{VO}_{2 \text { peak }}$ than the 300 -yd SWR time ( 74.8 vs $70.6 \%$, respectively).

The highest correlation $\left(R=.920 ; S E E=0.364 L \cdot \mathrm{min}^{-1}\right)$ for the 300-yd SWR time was achieved in Equation 6 when the variables of gender, body weight, and height/water depth were included. The identified predictor variables in Equation 6 combined to account for $84.6 \%$ of the variance in $\mathrm{VO}_{2 \text { peak. }}$ Gender and body weight were previously identified as appropriate variables to include in the development of regression equations to predict $\mathrm{VO}_{2 \text { peak (e.g., George }}$ et al., 1992, 1993; A. Jackson et al., 1992; Kline et al., 1987).

Likewise, when the variables of gender, body weight, and leg length were included with the 500-yd SWR time, the highest correlation and lowest SEE were achieved in Equation $4(R=.940$; $S E E=0.316$ L.min-1). In Equation 8, height/water depth was added to the variables of gender, body weight, and leg length for predicting $\mathrm{VO}_{2 \text { peak }}$ from the 500-yd SWR time, which resulted in $R=.940$ and $S E E=0.320 \mathrm{~L} \cdot \mathrm{min}^{-1}$. The predictor variables previously identified in both Equations 4 and 8 to predict $\mathrm{VO}_{2 \text { peak }}$ both combined to account for $88.4 \%$ of the variance in $\mathrm{VO}_{2 \text { peak }}$.

Stepwise multiple regression analyses revealed that in addition to the 300-yd SWR time, gender and body weight improved the prediction of $\mathrm{VO}_{2 \text { peak }}$ as the multiple correlation coefficients 
increased from .840 to .919 and the standard errors of estimate decreased from 0.480 to $0.360 \mathrm{~L} \cdot \mathrm{min}^{-1}$. It is interesting to note that the variance accounted for in $\mathrm{VO}_{2 \text { peak }}$ improved by $13.9 \%$ when the 300-yd SWR time, gender, and body weight were combined as compared to using only the 300 -yd SWR time to predict $\mathrm{VO}_{2 \text { peak. }}$

Similarly, the addition of gender, body weight, and leg length improved the prediction of $\mathrm{VO}_{2 \text { peak }}$ from the 500-yd SWR time, as the multiple correlation coefficients increased from .865 to .940 and the standard errors of estimate decreased from 0.443 to 0.316

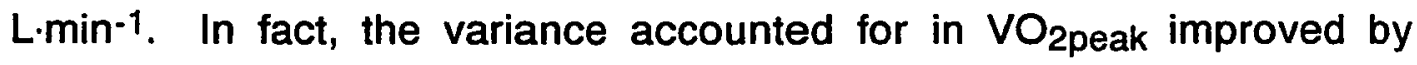
$13.6 \%$ when the 500-yd SWR time, gender, body weight, and leg length were combined as compared to using only the 500-yd SWR

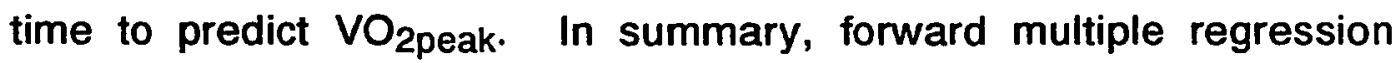
analyses which added height/water depth to the equations, developed through stepwise multiple regression analyses, generally tended to improve the prediction of $\mathrm{VO}_{2 p e a k}$, as evidenced by higher $R$ and lower SEE values, and improvements in the variance accounted for in $\mathrm{VO}_{2 \text { peak }}$ for comparable equations utilizing similar variables.

$$
\text { Cross-Validation Analysis }
$$

Cross-Validation of the Multiple Regression Equations Developed by Karninsky et al. (1993) for Predicting VO2peak

The three previously developed multiple regression equations for predicting $\mathrm{VO}_{2 p e a k}$ from 500-yd SWR time (Kaminsky et al., 1993) are displayed in Table 5. Cross-validation of the regression 


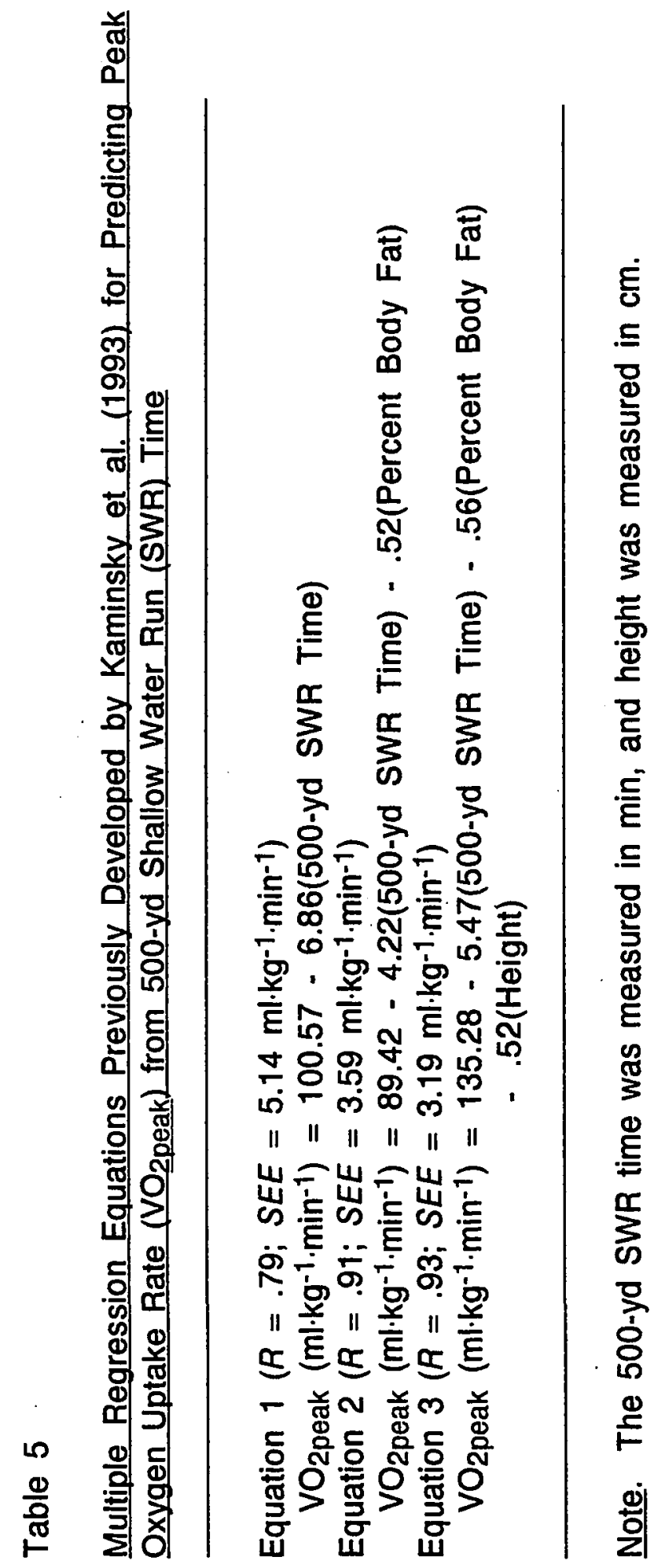


equations by Kaminsky et al. (1993) is summarized in Table 6 . Actual $\mathrm{VO}_{2 \text { peak, }}$ predicted $\mathrm{VO}_{2 \text { peak, }}$ and the mean difference between the actual $\mathrm{VO}_{2 \text { peak }}$ and predicted $\mathrm{VO}_{2 \text { peak }}$ (actual $\mathrm{VO}_{2 \text { peak }}$ - predicted $\mathrm{VO}_{2 \text { peak }}=$ mean difference) were calculated for the three equations developed by Kaminsky et al. (1993). The mean differences that were calculated for Equations $1\left(3.80 \pm 6.67 \mathrm{ml} \cdot \mathrm{kg}^{-1} \cdot \mathrm{min}^{-1}\right)$ and 2 $\left(1.86 \pm 5.18 \mathrm{ml} \cdot \mathrm{kg}^{-1} \cdot \mathrm{min}^{-1}\right)$ were within normal values; however, the mean difference for Equation $3\left(55.65 \pm 4.24 \mathrm{ml} \cdot \mathrm{kg}^{-1} \cdot \mathrm{min}^{-1}\right)$ was extraordinarily high. The large mean difference between the actual $\mathrm{VO}_{2 \text { peak }}$ and predicted $\mathrm{VO}_{2 \text { peak }}$ found in Equation 3 was attributed to a negative predicted $\mathrm{VO}_{2 \text { peak }}$ value of $-8.77 \pm 5.29 \mathrm{ml} \cdot \mathrm{kg}^{-1} \cdot \mathrm{min}^{-1}$.

The correlations between the actual and predicted $\mathrm{VO}_{2 \text { peak }}$ values were also calculated for the three equations. The correlation coefficients and standard errors of estimate calculated for Equations $1\left(r=.61 ;\right.$ SEE $\left.=5.98 \mathrm{ml} \cdot \mathrm{kg}^{-1} \cdot \mathrm{min}^{-1}\right)$ and $2(r=.76 ;$ SEE $=4.79 \mathrm{ml} \cdot \mathrm{kg}^{-1} \cdot \mathrm{min}^{-1}$ ) were moderate; however, Equation 3 had a high correlation and low SEE $\left(r=.84 ; S E E=2.87 \mathrm{ml} \cdot \mathrm{kg}^{-1} \cdot \mathrm{min}^{-1}\right)$. In other words, Equations 1, 2, and 3 accounted for $37.2 \%, 57.8 \%$, and $70.6 \%$ of the variance in $\mathrm{VO}_{2 \text { peak, }}$ respectively. The total error was

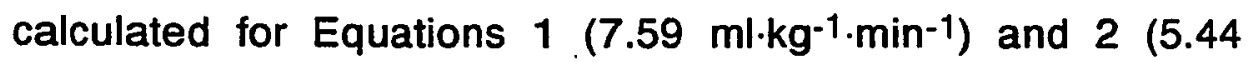
$\mathrm{ml} \cdot \mathrm{kg}^{-1} \cdot \mathrm{min}^{-1}$ ) were within reasonable ranges; however, the total error for Equation $3\left(55.81 \mathrm{ml} \cdot \mathrm{kg}^{-1} \cdot \mathrm{min}^{-1}\right)$ was enormously high, again due to the large mean difference between actual and predicted $\mathrm{VO}_{\text {2peak. }}$ 


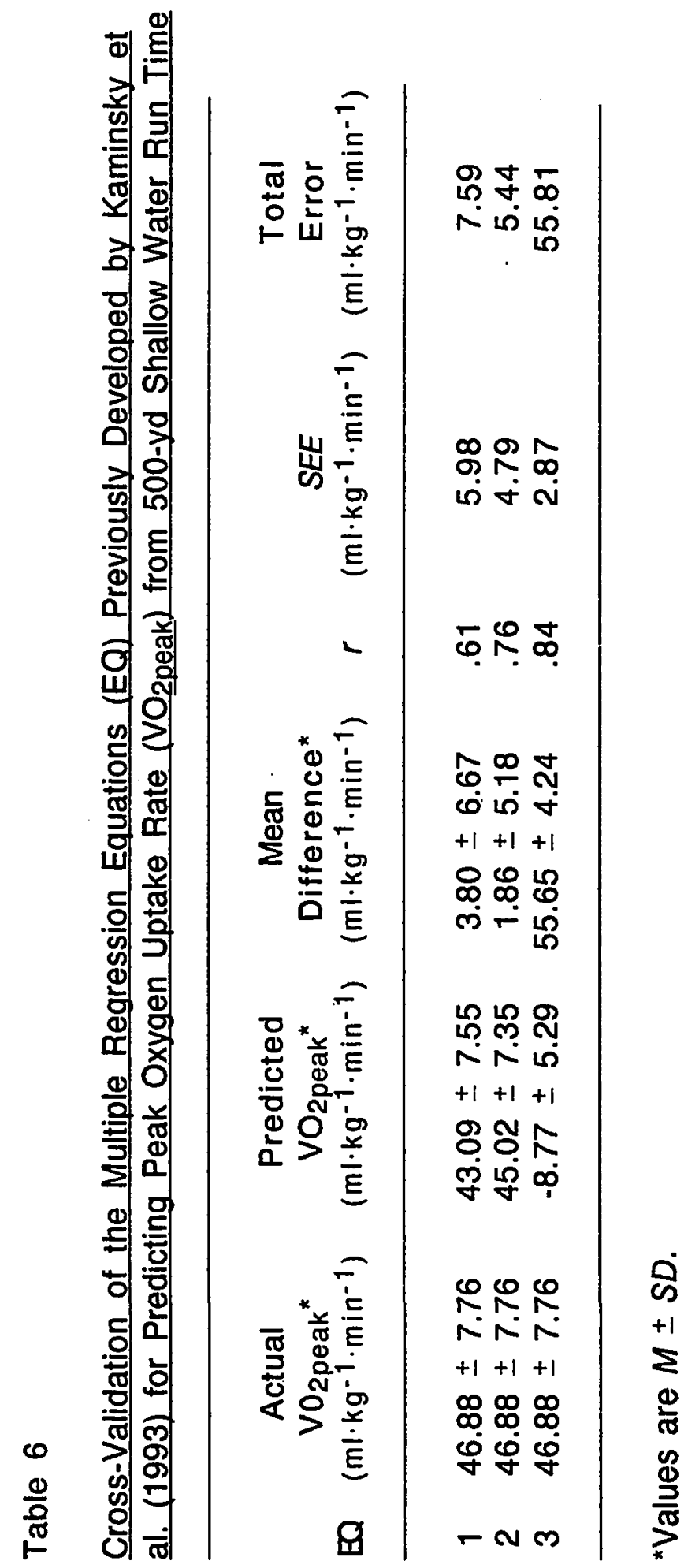


Summary and Discussion of the Cross-Validation of the Multiple Regression Equations Previously Developed by Kaminsky et al. (1993) for Predicting $\mathrm{VO}_{2 \text { peak }}$

As previously noted, the values measured in the current study resulted in the calculation of an unusually high mean difference $\left(55.65 \pm 4.24 \mathrm{ml} \cdot \mathrm{kg}^{-1} \cdot \mathrm{min}^{-1}\right)$ between the actual $\mathrm{VO}_{2 \text { peak }}$ and predicted $\mathrm{VO}_{2 \text { peak }}$ for Equation 3 developed by the Kaminsky et al. (1993) study. The extraordinarily high mean difference was attributed to a negative predicted $\mathrm{VO}_{2 \text { peak }}$ value $(-8.77 \pm 5.29$ $\left.\mathrm{ml}^{1} \mathrm{~kg}^{-1} \cdot \mathrm{min}^{-1}\right)$. Incredibly, when the mean data for the 500-yd SWR time, percent body fat, and height originally reported in the Kaminsky et al. (1993) study were calculated into Equation 3, an astonishingly high mean difference $\left(53.38 \mathrm{ml} \cdot \mathrm{kg}^{-1} \cdot \mathrm{min}^{-1}\right)$ was again found due to a negative predicted $\mathrm{VO}_{2 \text { peak }}$ value $(-9.76$ $\left.\mathrm{ml} \cdot \mathrm{kg}^{-1} \cdot \mathrm{min}^{-1}\right)$. A negative predicted $\mathrm{VO}_{2 p e a k}$ value is not possible, which suggested that serious error exists within the Kaminsky et al. (1993) Equation 3. Therefore, Equation 3 was not valid in the Kaminsky et al. (1993) study, nor did it cross-validate in the current study.

The correlation coefficients and standard errors of estimate calculated in the cross-validation of the regression equations were moderate in Equations $1\left(r=.61 ;\right.$ SEE $\left.=5.98 \mathrm{ml} \cdot \mathrm{kg}^{-1} \cdot \mathrm{min}^{-1}\right)$ and 2 $\left(r=.76 ;\right.$ SEE $\left.=4.79 \mathrm{ml} \cdot \mathrm{kg}^{-1} \cdot \mathrm{min}^{-1}\right)$. Equation 2 had a somewhat higher correlation and lower SEE than Equation 1, indicating that Equation 2 cross-validated to a more reasonable extent than 
Equation 1. Additionally, yet more specifically, the total error in the cross-validation of Equation $1\left(7.59 \mathrm{ml} \cdot \mathrm{kg}^{-1} \cdot \mathrm{min}^{-1}\right)$ was 2.45 $\mathrm{ml} \cdot \mathrm{kg}^{-1} \cdot \mathrm{min}^{-1}$ higher than the SEE $\left(5.14 \mathrm{ml} \cdot \mathrm{kg}^{-1} \cdot \mathrm{min}^{-1}\right)$ reported by Kaminsky et al. (1993); and the total error in the cross-validation of Equation 2 (5.44 $\left.\mathrm{ml} \cdot \mathrm{kg}^{-1} \cdot \mathrm{min}^{-1}\right)$ was only $1.85 \mathrm{ml} \cdot \mathrm{kg}^{-1} \cdot \mathrm{min}^{-1}$ higher than the SEE (3.59 $\left.\mathrm{ml} \cdot \mathrm{kg}^{-1} \cdot \mathrm{min}^{-1}\right)$ reported by Kaminsky et al. (1993). Therefore, in sum, Equation 2 cross-validated in the current study to a more reasonable extent than Equation 1.

The cross-validation of Equation 3 produced a strong correlation between actual and predicted $\mathrm{VO}_{2 p e a k}$ and a low SEE $\left(r=.84 ; S E E=2.87 \mathrm{ml} \cdot \mathrm{kg}^{-1} \cdot \mathrm{min}^{-1}\right)$; yet, the total error in Equation 3 (55.81 $\left.\mathrm{ml} \cdot \mathrm{kg}^{-1} \cdot \mathrm{min}^{-1}\right)$ was enormously high, indicating Equation 3 was an inaccurate and invalid equation. In fact, the total error in Equation 3 was $52.62 \mathrm{ml} \cdot \mathrm{kg}^{-1} \cdot \mathrm{min}^{-1}$ higher than the SEE $(3.19$

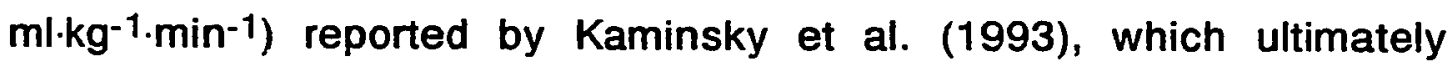
confirmed that Equation 3 was inaccurate, invalid, and did not cross-validate in the current study. In conclusion, Equation 2 crossvalidated in the current study to a more reasonable extent than Equations 1 and 3. 


\section{Chapter 5}

\section{CONCLUSIONS}

\section{Summary}

The purposes of the current study were to evaluate and compare the validity of both the 300-yd and 500-yd shallow water run field tests to determine peak aerobic power $\left(\mathrm{VO}_{2 p e a k}\right)$, and to cross-validate and improve the practical utility of a previously developed 500-yd SWR test. The subjects included 18 men and 18 women, aged 21.25 to $48.42 \mathrm{yr}$, who had laboratory assessments of height, leg length, body weight, and percent body fat; followed by a graded exercise treadmill test to determine $\mathrm{VO}_{2 \text { peak. Within a week }}$ of the laboratory assessments, the subjects completed a 300-yd and 500-yd SWR for time. SPSSX software was used for the statistical analysis. $\mathrm{VO}_{2 \text { peak }}$ was highly correlated to $300-\mathrm{y}$ and 500-yd SWR times $(r=-.84$ and -.87 , respectively). The strongest correlation was found between the 300-yd and 500-yd SWR times ( $r=.97$ ). Multiple regression analyses revealed that prediction of $\mathrm{VO}_{2 \text { peak }}$ from 300-yd SWR time improved by including gender and body weight $\left(R=.919 ; S E E=0.360 \mathrm{~L} \cdot \mathrm{min}^{-1}\right)$. Similarly, the prediction of $\mathrm{VO}_{2 \text { peak }}$ improved from the 500 -yd SWR time by including gender, body weight, and leg length $\left(R=.940 ; S E E=0.316 \mathrm{~L} \cdot \mathrm{min}^{-1}\right)$. Crossvalidation revealed that two of the three previously developed multiple regression equations for predicting $\mathrm{VO}_{2 \text { peak }}$ from 500-yd SWR time $\left(r=.61 ;\right.$ SEE $\left.=5.98 \mathrm{ml} \cdot \mathrm{kg}^{-1} \cdot \mathrm{min}^{-1}\right)$, and 500-yd SWR time and percent body fat $\left(r=.76 ;\right.$ SEE $\left.=4.7 \mathrm{ml} \cdot \mathrm{kg}^{-1} \cdot \mathrm{min}^{-1}\right)$, were 
moderately valid. Equations were also developed for use in pools of water depths that differed from the depth used in the current study. In conclusion, the 300-yd and 500-yd SWR tests, especially if used with the discussed variables, can provide accurate and valid estimates of aerobic power in young men and women.

Conclusions

The following conclusions were drawn from the results of the current study:

1. The predictor variables of height, and 300-yd and 500-yd SWR times, correlated highly with $\mathrm{VO}_{2 p e a k}$. Likewise, height and leg length were highly correlated to the 300-yd and 500-yd SWR times. As expected, height and leg length were highly correlated with one another. Again, as presumed, the 300-yd and 500-yd SWR heart rates were also highly correlated with one another. The strongest correlation was found between the 300-yd and 500-yd SWR times. 2. The predictor variables of 300-yd SWR time, gender, and body weight combined to account for $84.5 \%$ of the variance in $\mathrm{VO}_{2 p e a k}$. 3. The predictor variables of 500-yd SWR time, gender, body weight, and leg length combined to account for $88.4 \%$ of the variance in $\mathrm{VO}_{2 \text { peak. }}$

4. The multiple regression Equations 1 and 2 developed by Kaminsky et al. (1993) were reasonable predictors of $\mathrm{VO}_{2 \text { peak; }}$ however, Equation 3 was inaccurate, and therefore, did not cross-validate in the current study. 
Weaknesses of the Study

Weaknesses of the current study were as follows:

1. Prior to the actual SWR testing, a formal practice session was required to familarize subjects with the required shallow water running technique. Subjects who were not experienced with the shallow water running technique may have needed additional instruction to control for a learning effect during the actual testing. 2. Subjects did not wear protective footing so the findings of the current study would be generalizable to other populations and pools; however, error due to slipping on the pool bottom, and/or painful footing, would have been minimized during the actual testing had the subjects worn protective footing.

3. The Polar Vantage $X L^{T M}$ heart rate monitors were not as reliable as anticipated during the SWR tests.

\section{Recommendations for Future Research}

Recommendations for future research are as follows:

1. Cross-validation of the regression equations are recommended prior to their use with other samples and pools.

2. Accurate and valid normative data for the 300-yd and 500-yd SWR times need to be established. The normative data for 500-yd SWR times (Robbins et al.,1991) needs to be re-evaluated and crossvalidated in other populations and pools.

3. The relationships between rating of perceived exertion, heart rate, and exercise intensity during water-based exercise also warrants further investigation. 


\section{References}

American College of Sports Medicine. (1990). The recommended quantity and quality of exercise for developing and maintaining cardiorespiratory and muscular fitness in healthy adults. Medicine and Science in Sports and Exercise, 22, 265-274.

American College of Sports Medicine. (1991). Guidelines for exercise testing and prescription (4th ed.). Philadelphia: Lea \& Febiger.

Astrand, P. O., \& Ryhming, I. (1954). A nomogram for calculation of aerobic capacity (physical fitness) from pulse rate during submaximal work. Journal of Applied Physiology. 7, 218-221.

Astrand, P. O., \& Saltin, B. (1961). Oxygen uptake during the first minutes of heavy muscular exercise. Journal of Applied Physiology, 16, 971-976.

Balke, B. (1963). A simple field test for the assessment of physical fitness (Civil Aeromedical Research Institute Report 63-6, pp. 1-8). Oklahoma City, OK: Federal Aviation Agency.

Baumgartner, T. A., \& Jackson, A. S. (1991). Measurement for evaluation in physical education and exercise science (4th ed.). Dubuque, IA: William C. Brown.

Blair, S. M., Kohl, H. W., III., Paffenbarger, R. F., Clark, D. G., Cooper, K. H., \& Gibbons. (1989). Physical fitness and all-cause mortality: A prospective study of healthy men and women. Journal of the American Medical Association, 262, 2395-2401.

Body composition: A round table. (1986). The Physician and Sports Medicine, 14(3), 144-162.

Bruce, R. A., Kusumi, R., \& Hosmer, D. (1973). Maximal oxygen intake and nomographic assessment of functional aerobic impairment in cardiovascular disease. American Heart Journal, 85, 546562. 
Conley, D. S., Cureton, K. J., Dengel, D. R., \& Weyland, P. G. (1991). Validation of the 12-minute swim as a field test of peak aerobic power in young women. Medicine and Science in Sports and Exercise, 23, 766-773.

Conley, D. S., Cureton, K. J., Hinson, B. T., Higbie, E. J., \& Weyland, P. G. (1992). Validation of the 12-minute swim as a field test of peak aerobic power in young women. Research Quarterly for Exercise and Sport, 63, 153-161.

Cooper, K. H. (1968). A means of assessing maximal oxygen uptake: correlation between field and treadmill testing. Journal of the American Medical Association, 203, 135-138.

Cooper, K. H. (1977). The aerobics wav. New York: M. Evans and Co.

Custer, S. J., \& Chaloupka, E. C. (1977). Relationship between predicted maximal oxygen consumption and running performance of college females. Research Quarterly, 48, 47-50.

Doolitte, T. L., \& Bigbee, R. (1968). The twelve minute walk-run: a test of cardiorespiratory fitness of adolescent boys. Research Quarterly, 39, 491-495.

Falls, H. B., Ismail, A. H., \& MacLeod, D. F. (1966). Estimation of maximum oxygen uptake in adults from AAHPER youth fitness test items. Research Quarterly, 37, 192-201.

Fox, E. L. (1973). A simple, accurate technique for predicting maximal aerobic power. Journal of Applied Physiology, 35. 914-916.

George, J. D., Vehrs, P. R., Allsen, P. E., Fellingham, \& Fisher, A. G. (1992). Development of a one-mile steady-state track jog for the prediction of $\mathrm{VO}_{2 \max }$. Medicine and Science in Sports and Exercise, 24(Suppl. 1112), S186. 
George, J. D., Vehrs, P. R., Allsen, P. E., Fellingham, \& Fisher, A. G. (1993). $V_{2} O_{2}$ ax estimation from a submaximal 1-mile track jog for fit college-age individuals. Medicine and Science in Sports and Exercise, 25, 401-406.

Getchell, L. H., Kirkendall, D., \& Robbins, G. (1977). Prediction of maximal oxygen uptake in young adult women joggers. Research Quarterly, 48, 61-67.

Hermiston, R. T., \& Faulkner, J. A. (1971). Prediciton of maximal oxygen uptake by a stepwise regression technique. Journal of Applied Physiology, 30, 833-837.

Heyward, V. H. (1984). Designs for fitness. Minneapolis: Burgess Publishing Co.

Jackson, A., Jackson, A. S., \& Frankiewicz, R. G. (1979). The construct and concurrent validity of a 12-min crawl stroke swim as a field test of swimming endurance. Research Quarterly, 50, 641-648.

Jackson, A., Solomon, J., \& Stusek, M. (1992). One-mile walk-test: reliability, validity, and norms for young adults. Research Quarterly for Exercise and Sport. 63(Suppl. 1), A-52.

Jackson, A. S. (1984). Research design and analysis of data procedures for predicting body density. Medicine and Science in Sports and Exercise, 16, 616-620.

Johnson, D. J., Oliver, R. A., \& Terry, J. W. (1979). Regression equation for prediction of performance in the twelve minute run-walk test. Journal of Sports Medicine, 19, 165-170.

Kaminsky, L. A., Wehrill, K. W., Mahon, A. D., Robbins, G. C., Powers, D. L., \& Whaley, M. H. (1993). Evaluation of a shallow water running test for the estimation of peak aerobic power. Medicine and Science in Sports and Exercise, 25, 1287-1292. 
Katch, F. I., Pechar, G. S., McArdle, W. D., \& Weltman, A. L. (1973). Relationship between individual differences in a steady pace endurance running performance and maximal oxygen intake. Research Quarterly, 44, 206-215.

Kent, M. (1994). The Oxford dictionary of sports science and medicine. New York: Oxford University Press.

Kline, G. M., Porcari, J. P., Hintermeister, R., Freedson, P. S., Ward, A., McCarron, R. F., Ross, J., \& Rippe, J. M. (1987). Estimation of $\mathrm{VO}_{2 \max }$ from a one-mile track walk, gender, age, and body weight. Medicine and Science in Sports and Exercise, 19, 253259.

Koszuta, L. E. (1986). Water exercise causes ripples. The Physician and Sportsmedicine, 14(10), 163-167.

Maksud, M. G., Cannistra, C., \& Dublinski, D. (1976). Energy expenditure and $\mathrm{VO}_{2 \max }$ of female athletes during treadmill exercise. Research Quarterly, 47, 692-697.

Maksud, M. G., \& Coutts, K. D. (1971). Application of the 12-minute run-walk test to young males. Research Quarterly, 42, 54-59.

Margaria, R., Aghemo, P., \& Rovelli, E. (1965). Indirect determination of maximal $\mathrm{O}_{2}$ consumption in man. Journal of Applied Physiology, 20, 1070-1073.

Mastropaolo, J. A. (1970). Prediction of maximal $\mathrm{O}_{2}$ consumption in middle-aged men by multiple regression. Medicine and Science in Sports, 2, 124-127.

McArdle, W. D., Katch, F. I., \& Katch, V. L. (1991). Exercise physiology: Energy, nutrition, and human performance (3rd ed.). Philadelphia: Lea \& Febiger.

McCutcheon, M. C., Sticha, S. A., Giese, M. D., \& Nagle, F. J. (1990). A further analysis of the 12-miute run prediction of maximal aerobic power. Research Quarterly for Exercise and Sport, 61 , 280-283. 
MedGraphics cardiopulmonary exercise testing system (CPX/D) user's manual. (1993). St. Paul, MN: Medical Graphics Corporation.

Midtlyng, J., \& Nelson, C. V. (1991). National survey of water exercise participants. In Aquatic Exercise Resource Series: Aquatic Exercise Research. Port Washington, WI: Aquatic Exercise Association.

Pollock, M. L., Bohannon, R. L., Cooper, K. H., Ayres, J. J., Ward, A., White, S. R., \& Linnerud, A. C. (1976). A comparative analysis of four protocols for maximal treadmill stress testing. American Heart Journal, 92, 39-46.

Pollock, M. L., Schmidt, D. H., \& Jackson, A. S. (1980). Measurement of cardiorespiratory fitness and body composition in the clinical setting. Comprehensive Therapy, 6, 12-27.

Ribisl, P. M., \& Kachadorian, W. A. (1969). Maximal oxygen intake prediction in young and middle-aged males. The Journal of Sports Medicine and Physical Fitness, 9, 17-22.

Robbins, G., Powers, D., \& Burgess, S. (1991). A wellness way of life. Dubuque, IA: William C. Brown.

Rogers-Johnson, M. J., Heyward, V. H., Schau, C., \& Cagle, T. G. (1992). Development of a cardiorespiratory field test using an aerobic dance protocol. Medicine and Science in Sports and Exercise, 24(Suppl. 407), S68.

Safrit, M. J., Glaucia Costa, M., Hooper, L. M., Patterson, P., \& Ehlert, S. A. (1988). The validity generalization of distance run tests. Canadian Journal of Sport Sciences, 13, 188-196.

Shepard, R. J. (1968). The maximum oxygen uptake: an international reference standard of cardiorespiratory fitness. Bulletin of the World Health Organization, 38, 757-764. 
Sherman, N. W., Michaud, T. J., \& Ryan, N. D. (1993). Estimating $\mathrm{VO}_{2 \max }$ from submaximal aquarunning. Research Quarterly for Exercise and Sport, 64, A-35.

Siri, W. E. (1961). Body composition from fluid spaces and density: analysis of methods. In J. Brozek \& A. Henschel (Eds.), Techniques for measuring body composition (pp. 223-244). Washington, DC: National Academy of Sciences, National Research Council.

Taylor, H. L., Buskirk, E., \& Henschel A. (1955). Maximal oxygen intake as an objective measure of cardio-respiratory performance. Journal of Applied Physiology. 8, 73-80. 
APPENDIX A

\section{STATEMENT OF INFORMED CONSENT}

FOR BODY COMPOSITION AND SIZE

\section{AND CARDIORESPIRATORY ENDURANCE}




\title{
EVALUATION AND COMPARISON OF THE 300-YARD AND 500-YARD SHALLOW-WATER RUNS AS FIELD TESTS OF AEROBIC POWER
}

\author{
STATEMENT OF INFORMED CONSENT \\ FOR BODY COMPOSTTION \\ AND SIZE AND AEROBIC POWER
}

\section{Invitation to Participate}

You are invited to participate in a study of two shallowwater runs as field tests of aerobic power. The study will be conducted at the San Jose State University campus.

\section{Basis for Selection}

You have been selected as a participant because you are a healthy female aged 18 to 50 years old, or a male aged 18 to 40 years old. Should you decide to participate, your response to a health history questionnaire will be reviewed by an exercise physiologist and if satisfactory, you will be asked to participate in the tests described below. 
Purposes of the Study

The purposes of the study will be to determine:

1. To what extent the 300-yd shallow-water run field test relates to aerobic power, in women and men who vary in height, body weight, percent body fat, leg length, and age? 2. To what extent the 500-yd shallow-water run field test relates to aerobic power, in women and men who vary in height, body weight, percent body fat, leg length, and age? 3. To what extent the 300-yd shallow-water run field test compares to the 500-yd shallow-water run field test in relation to aerobic power, in women and men who vary in height, body weight, percent sody fat, leg length, and age?

4. To what extent do the equations developed by Kamisky et al. (1993) cross-validate in an independent sample of subjects?

\section{Explanation of Procedures}

\section{Prior to Testing Methodology}

Prior to testing you will complete and sign a consent form; and a health/medical history questionnaire, to be approved by the Human Subjects Institutional Review Board of San Jose State University.

\section{Testing Methodology}

After approval by the Human Subjects Institutional Review Board of San Jose State University, you will practice 
both the shallow-water running (SWR) techinique and use of the rating of perceived exertion (RPE) scale while wearing a swim suit and a Polar Vantage XL Heart Rate monitor. Immediately following the practice session, you will perform a 5-min trial SWR. Within a week after the practice session/trial run, you will have laboratory assessments of body composition (percent body fat) and size (height, leg length, and body weight), and perform a maximal graded exercise test (GXT). Within a week after the laboratory assessments, you will complete the testing by performing "best effort" 300-yd and 500-yd shallow-water runs in a random order.

\section{Body Composition and Size}

Your body weight will be assessed on a platform scale and your height and leg length will be measured on a wall scale with a Broca plane. Your body composition will be determined via skinfold measurements.

\section{Maximal Test}

\section{Aerobic Power Test}

Your maximal aerobic power, or cardiorespiratory endurance, will be determined from a test which involves running on a treadmill at progressively increasing workloads. You will wear a pair of socks, athletic shoes, and appropriate 
exercise clothing. You will be fitted with mouth piece and nose clips and will inhale room air continually throughout the maximal graded exercise test. Your expired air will be collected through the mouth piece connected to rubber tubing. A Cardiopulmonary Exercise System will collect your expired air samples breath-by-breath in order to measure expired ventilation rate, oxygen uptake rate, carbon dioxide production rate, and $R$ values continually during the test.

A electrocardiograph will be used to monitor your heart rate and ECG rhythms continually during the test. Your heart rate will be monitored with five electrodes attached to your upper body near your right and left arm, right and left leg, and the left side of your chest. The leads will monitor all cardiac electrical patterns and obtain heart rate during the last ten seconds of each minute of the test.

You will begin by walking on the treadmill at $1.7 \mathrm{mph}$ and $10 \%$ grade for three minutes and continues with workload increases in speed and grade which approximate one metabolic equivalent $\left(3.5 \mathrm{ml} \cdot \mathrm{kg}^{-1} \cdot \mathrm{min}^{-1}\right)$ every three minutes until voluntary exhaustion is achieved. For the purpose of this study, you will voluntarily terminate the test after giving a "last-minute" signal. Following completion of the test, the resistance will be reduced so recovery will be comfortable. 
Dr. Craig J. Cisar, Certified Exercise Test Technologist by the American College of Sports Medicine, will be present during the administration of the maximal oxygen uptake test. Certified CPR personnel will also be present during testing. The test will be terminated for any of the following reasons: (1) you request to terminate the test; (2) failure of your heart rate to increase with increasing workloads; (3) pain or fatigue as indicated by decreased coordination or pallor; (4) abnormalities on the ECG reading; or (5) equipment failure (ACSM, 1991).

\section{Submaximal Tests}

\section{Shallow-Water Run Tests}

You will wear a swim suit and a Polar Vantage XL Heart Rate Monitor during both tests. Prior to the actual SWR tests, you will be required to adequately warm-up by water walking and jogging for 2-3 minutes followed by stretching. The SWR tests will begin with your hand touching the pool wall. You will remain in a designated marked "lane" in an effort to keep you running straight throughout each SWR test.

You will be encouraged to run as fast of a pace as possible during both tests. Lap counters will sit at the ends of the pool revealing and recording the number of laps you are completing, RPE, and time at the completion of every two laps. 
One lap is designated at each turn. You will touch the wall with one hand before running another lap. During the turn, you will be given verbal encouragement to do the best you can. Your arms will move similar to the arm movements used to swim the front crawl. Specifically, the 'recovery' portion of the armstroke will be performed through the air; and, the 'propulsive' phase will be performed as the fingertips enter the water and continue to sweep the submerged hand and arm past the hips. The level that the arm will be submerged will depend upon your height, need for balance, and possible swimming skill. The total time of the run will be recorded in minutes and seconds.

The run will end when you complete the 300-yard (12 laps) or 500-yard (20 laps) by touching the wall, or sooner if you exhibit dizziness, pain, or fatigue as indicated by decreased coordination or pallor. The time of the 300-yd shallow-water run will be recorded in minutes and seconds from the time you leave the pool wall, run the entire 12 laps, until the final lap wall is touched with one hand. The time of the 500-yd shallow-water run will be recorded in minutes and seconds from the time you leave the pool wall, run the entire 20 laps, until the final lap wall is touched with one hand. 


\section{Discomforts and Risks}

\section{Cardiorespiratory Endurance Test}

You may experience some discomfort and dryness in the mouth, throat, and chest during the graded exercise test. Discomfort may come from breathing through a mouth piece with a nose clip in place. You may also experience discomforts commonly associated with exercise: sweating, increased heart rate, breathing rate, and body temperature; and fatigue. Changes that may be anticipated at or near the end of the exercise test include abnormal blood pressure, fainting, dizziness, muscle fatigue or cramps, nausea, and abnormalities in heart beat (some of these could result in death). Individuals will be excluded from participation in this investigation when abnormalities are detected in electrocardiographic recordings or medical history indicates that testing is contraindicated. During exercise you may experience heartbeat abnormalities. If these are detected, the test will be stopped immediately. You may be fatigued, lightheaded, and slightly nauseous for a short time following the exercise test.

Submaximal Water Run Tests

As with any pool situation, chlorine irritation, swallowing of water, and choking are possible. There may be discomfort associated with an all-out effort run in the water. 


\section{Benefits from Participation in the Study}

You will benefit from the testing by receiving an accurate assessment of your body composition and cardiorespiratory fitness. The information collected may be used as the basis of an aerobic training program.

Compensation for Participation in the Study

There will be no compensation for participation in the study.

\section{Assurance of Confidentiality}

Your test data will be coded by number, not by subject name, to ensure maximum confidentiality. Your data will be kept in a locked file cabinet by the primary investigator until completion of the study, and will then be destroyed. The results of the investigation may be used for research publication and presentation; however, your right to confidentiality and anonymity will be protected.

\section{Withdrawal from the Study}

Your participation in this study is completely voluntary. You may withdraw your consent and discontinue participation at any time (including during the testing) without prejudice. You are free to decline to answer any specific item or question on the medical history questionnaire. 
If you have questions about the investigation now or during the testing, please feel free to ask. If additional questions come up later, or in case of an emergency, call Rebecca Cisar 408-259-2405, Dr. Susan Wilkinson 408-9243034, or Dr. James Bryant 408-924-3010 and they will respond. In case of any complaints during or after the testing, you may contact Dr. Serena Stanford, Associate Academic Vice President of Graduate Studies and Research 408-924-2480.

\section{Consent}

By signing this form, you are agreeing that:

(a) you have decided to participate in this study having read the information provided above;

(b) you understand the discomforts and risks involved;

(c) you understand that you can withdraw anytime; and

(d) you understand that your name will be kept confidential except with your expressed consent.

You will be given a copy of this consent form for your personal records.

Signature of Test Subject Date

Print Name 


\section{APPENDIX B}

PRE-EXERCISE TESTING

\section{HEALTH STATUS QUESTIONNAIRE}




\section{APPENDIX B \\ PRE-EXERCISE TESTING HEALTH STATUS QUESTIONNAIRE}

Name

Number

Date

A. Health Status: Check problem areas you previously or currently have experienced:

( ) High Blood Pressure

( ) Heart Disease of Dysfunction

( ) Peripheral Cirulatory Disorder

( ) Lung Disease or Dysfunction

( ) Arthritis or Gout

( ) Edema

( ) Epilepsy

( ) Multiple Sclerosis

( ) High Blood Cholesterol or triglyceride levels

( ) Acute Infection

( ) Diabetes or Blood Sugar

( ) Anemia

( ) Hernias

( ) Thyroid Dysfunction

( ) Pancreas Dysfunction

( ) Liver Dysfunction

( ) Kidney Dysfunction

( ) Neural Dysfunction

( ) Other(s) you think we should know about

B. Family History: Check if any of your blood relatives have or have had any of the following:

( ) Heart attacks or strokes prior to age 50

( ) Elevated Blood Cholesterol or triglceride levels

( ) Diabetes

( ) Heart Disease

( ) High Blood Pressure

( ) Other(s) you think we should know about

C. Physical Perceptions: Indicate any unusual sensations or perceptions you have had during or shortly after physical activity (PA); or during sedentary periods (SED):

PA SED

( ) ( ) Chest Pain

( ) ( ) Heart Palpitations

( ) ( ) Unusually rapid breathing

( ) () Overheating

( ) ( ) Muscle Cramping

( ) ( ) Muscle Pain

( ) ( ) Joint Pain

( ) ( ) Other(s)

D. Current Habits: Check any of the following that apply:

PA SED
( ) ( ) Nausea

( ) ( ) Light Headedness

( ) ( ) Loss of Balance

( ) ( ) Loss of Coordination

( ) ( ) Extreme Weakness

( ) ( ) Numbness

( ) ( ) Mental Confusion 


\section{Smoking}

Do you smoke? Yes ( ) No ( )

If yes, how many per day?

How many years?

In case you stopped, when did you smoke?

How many years?

Diet

What is your weight now?

At age 21?

Are you dieting?

One year ago?

Exercise

( ) Regularly do manual garden or yard work

( ) Regularly go for long walks: How far? Freqency per week

( ) Frequently rides a bicycle: How far? Frequency per week

( ) Participates in aerobic dance program:

Frequency per week?

( ) Uses the Stairmaster: How long?

Frequency per week?

( ) Running: How far? Frequency per week?

( ) Lift weights: Frequency per week?

( ) Engage in a sports program more than once per week. If so, what does this consist of?

( ) Other exercise(s) you participate in?

How long or far? Frequency per week?

Current Medication Usage (List the drug name and the condition being managed)

Medication

Condition 